\title{
PAINT-BY-NUMBERS TAX LAWMAKING
}

\author{
Michael J. Graetz*
}

Introduction $\ldots \ldots \ldots \ldots \ldots \ldots \ldots \ldots \ldots \ldots \ldots \ldots \ldots \ldots \ldots, 609$

I. The Relevant Staffs............................. 614

II. Distributional Tables ............................ 617

A. Impossible Goals and Impractical Tasks ............ 619

B. Where Has Gini Gone? ..................... 620

C. Staff Disagreements in Constructing Distributional Tables .................................... 624

1. Distributing Changes in Taxes vs. Changes in "Burden" .................................... 624

2. The Measurement of Income ................ 634

3. The Unit of Analysis: Families, Couples, Individuals, or Households ............................... 637

4. The Relevant Time Horizon.................... 640

5. Tax Incidence Assumptions .................. 640

D. Controversial Areas of Staff Agreement ............. 647

1. Tax Capitalization and Implicit Taxes ........... 647

2. Lifetime vs. Annual Income .................. 651

3. Distributing Transfers as Well as Taxes ........... 657

4. Benefit Taxes and User Charges................ 661

5. Mandates and Regulations ................... 661

6. Federalism................................ 664

7. International Aspects....................... 665

E. A Preliminary Conclusion Regarding Distribution

Tables....................................... 666

III. Revenue Estimates ........................... 668

A. Overview of the Revenue Estimating Process ......... 668

B. Asking the Wrong Question $. \ldots \ldots \ldots \ldots \ldots \ldots \ldots \ldots, 672$

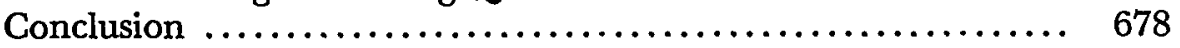

\section{INTRODUCTION}

Although their meaning and contours have long been controversial, the general criteria for evaluating changes in tax law enjoy both stability and consensus. At least since Adam Smith, there has been virtually universal agreement that the nation's tax law should be fair, economically efficient, and simple to comply with and to administer. Tax law changes

* Justus S. Hotchkiss Professor of Law, Yale Law School. I want to thank William Andrews, David Bradford, Daniel Halperin, Louis Kaplow, Alvin Klevorick, Jeff Lehman, Reed Shuldiner, Alvin Warren, and participants in conferences and workshops at the American Enterprise Institute, the Harvard Law School, the University of Pennsylvania Law School, and Yale Law School for helpful comments. I also want to thank José Esteves for producing the graphs contained herein, Anand Raman for research assistance, and the American Enterprise Institute for financial assistance. 
should be designed to make the law more equitable, easier to comply with, more conducive to economic growth, and less likely to interfere with private economic decisionmaking.

Precisely what these criteria imply for policymaking is controversial, however. Fairness is often said to require that people with equal ability to pay taxes pay equal amounts of tax, and those with greater ability to pay, pay more. Disputes have long raged over the traits relevant to evaluate whether people's circumstances are appropriately similar to warrant similar tax treatment and over the standards for evaluating peoples' relative abilities to pay taxes. Nonetheless, a "fair" distribution of the tax burden among people at different levels of income has long been regarded as a necessary attribute of a just tax system, and its assessment is essential to evaluate how a nation's tax law-or proposed changes in it-measure up. Likewise, answers to questions regarding the economic effects of proposed or enacted tax legislation are routinely disputed. Even the need to finance budget expenditures with revenues-a seemingly straightforward imperative-proves controversial in its execution. The pursuit of simplicity is frequently a bystander. Conflict among these concerns is inevitable-conflict that demands, and is reflected in, inevitable political compromise. Tradeoffs among these goals are the stuff from which tax legislation is made.

As an example, in the 1981 tax legislation ${ }^{1}$ horizontal equity-and some contend vertical equity - was put aside in a quest for economic growth. ${ }^{2}$ The 1986 Tax Reform Act $^{3}$ was motivated by an effort to restore and improve horizontal equity and to reduce the tax law's interference with economic decisionmaking in private markets. ${ }^{4}$ In combination, the 1981 and 1986 Acts reduced the marginal tax rate at the top of the income scale from seventy to twenty-eight percent. Democrats argued subsequently that Republican tax policy of the 1980s favored the rich and disadvantaged the middle class. This political attack criticized "trickle down" economics, promising cuts to the "excessive" tax burdens on the middle class and increases in the "inadequate" taxes on the rich. These arguments became a central theme in the negotiations leading to the Budget Act of 1990,5 in the 1990 mid-term elections, and in President Clinton's 1992 campaign. They also played an important role in the en-

1. Economic Recovery Tax Act of 1981, Pub. L. No. 97-34, 95 Stat. 172 (codified as amended in scattered sections of 26 U.S.C.).

2. C. Eugene Steuerle, The Tax Decade: How Taxes Came to Dominate the Public Agenda 107 (1992). For readers not familiar with the terms, horizontal equity refers to similar treatment of people similarly situated; vertical equity refers to the fairness of the distribution of taxes at different levels of income, consumption, or wealth.

3. Tax Reform Act of 1986, Pub. L. No. 99-514, 100 Stat. 2085 (codified as amended in scattered sections of 26 U.S.C.). (1988).

4. See Michael J. Graetz, The Truth About Tax Reform, 40 U. Fla. L. Rev. 617, 623

5. Omnibus Budget Reconciliation Act of 1990, Pub. L. No. 101-508, 104 Stat. 1388 (1990) [hereinafter OBRA 90]. 
actment of the 1993 Budget Act, ${ }^{6}$ which raised the top rate to 39.6 percent and narrowly passed Congress without a single Republican vote.

Perhaps most important to tax policymakers, the public seems responsive to the perceived fairness of taxes-particularly of their own tax burdens, but also the burdens of others. ${ }^{7}$ As a practical inatter, politicians may be voted out of office and tax compliance may decline if taxes are perceived by the public to be unfair. Coupled with the public's general anti-tax attitude, press reports, congressional staff studies, and academic studies describing recent shifts in the nation's distribution of income and wealth in favor of the wealthy have heightened the concerns of both the public and their representatives with issues of tax distribution. Public interest in distributional questions may explain why politicians of all political stripes seem to want to argue that their policies are (or were) progressive, thereby confirming the 1976 observation of conservative Treasury Secretary William Simon that " $[t]$ here appears to be widespread consensus that an element of progression is desirable in the tax structure."8

But Congress has not been free simply to adjust the distribution of its constituents' taxes without taking into account budgetary pressures. During the past decade, the federal deficit has received substantial legislative attention as Congress has become increasingly concerned with this issue. The Economic Recovery Tax Act of $1981^{9}$ was the last tax legislation designed to reduce revenues, and every tax act after 1986 has been intended to raise revenues. The Reagan Administration and Congress agreed that the far-reaching Tax Reform Act of 1986 would be both revenue and distributionally neutral; its provisions were intended neither to increase nor reduce anticipated overall revenues nor shift the tax burden across differmg levels of income. ${ }^{10}$ In writing the 1986 Act, Congressional staff and decisionmakers used revenue and distributional data creatively to constrain and guide tax policymaking toward substantive outcomes based on widely shared normative goals and legislative directions. ${ }^{11}$

In contrast, since 1986, virtually all significant tax legislation has been a revenue-raising part of "Omnibus Budget Reconciliation Act" legislation with the principal mission of deficit containment. In both 1990 and 1993, specific deficit goals-reductions in projected five-year budget

6. Omnibus Budget Reconciliation Act of 1993, Pub. L. No. 103-66, 1993 U.S.C.C.A.N. (107 Stat) 312 [hereinafter OBRA 93].

7. See, e.g., Steven M. Sheffrin, What Does the Public Believe About Tax Fairness?, 46 Nat'l Tax J. 301, 302-03 (1993).

8. Letter from Secretary of Treasury William Simon to Mrs. Llewellyn Lowe (Treas. Doc. 76-25), summarized in Consumption Type Income Tax, Tax Notes, Dec. 27, 1976, at 11.

9. Economic Recovery Tax Act of 1981, Pub. L. No. 97-34, 95 Stat. 172.

10. See Graetz, supra note 4 , at 623-25.

11. See, e.g., Steuerle, supra note 2, at 1-2 (discussing legislative goals of lowering tax rates and broadening income tax base, particularly through elimination of tax shelters). 
deficits by a total of $\$ 500$ billion in each case-dominated the policymaking process. ${ }^{12}$ The budgetary rules of the 1990 and 1993 Acts demanded that any revenue reducing measures be paid for either through offsetting revenue increases or spending reductions; during consideration of both of these Acts, Democratic majorities in Congress also insisted that tax increases increase the progressivity of the federal tax system. Indeed, in 1993, President Clinton demanded, and the Democratic congressional majority agreed, that at least seventy percent of tax increases be levied on people with incomes of at least $\$ 100,000 .^{13}$ In recent years, achieving specific revenue and distributional numbers have become policy goals themselves.

The political focus on balancing traditional tax policymaking concerns for improving equity and economic efficiency has been subordinated in recent legislation to reflect the overriding goal of insuring specific annual revenue effects of proposed tax policy changes over the "budget period" (generally five years, but, under the 1993 Budget Act, ten years in some cases). For example, in the 1993 Act, personal income taxes were made retroactive to the beginning of 1993 (with deferred payments allowed for three years) solely to satisfy five-year revenue targets. ${ }^{14}$ In addition, sizeable penalties on marriage were enacted for high-income taxpayers in 1993 for the sole purpose of conforming to a specific combination of revenue and distributional targets, without violating the President's decision not to raise the top income tax rate above forty percent. ${ }^{15}$

This increased reliance on distributional tables and revenue estimates as outcome-determinative factors in tax legislation presents two quite different problems. Although it is important to know the likely effect of proposed tax legislation on total federal finances, with regard to revenue effects, policymakers are often asking the wrong question. Rather than looking to the long-term or even overall effects of tax legislation on federal revenues, Congress looks only to annual revenue effects over a five- or ten-year period. Indeed, Congress has bound itself legislatively to focus on this question through statutory budgetary requirements.

12. See Budget Talks Concluded, Tax Notes Today, Oct. 1, 1990, available in LEXIS, Fedtax Library, TNT File (discussing 1990 budget goals).

13. See OBRA 93, supra note 6; Senate Passes Reconciliation Bill, 50-49, Tax Notes Today, July 8, 1993, available in LEXIS, Fedtax Library, TNT File; Tax Bill's Stiff Wedlock Penalty Tests Limits of 'Family Values,' Tax Notes Today, July 6, 1993, available in LEXIS, Fedtax Library, TNT File.

14. See OBRA 93, supra note 6 , at $\$ 13201$ (c) (making provisions retroactive); id. at $\$ 13201$ (d) (allowing payment in installments).

15. See Michael J. Graetz, Tax Policy at the Beginning of the Clinton Administration, 10 Yale J. on Reg. 561, 569 (1993) (illustrating that tax penalty on marriage for high income taxpayers exceeds $\$ 13,000$ a year). For a discussion of the marriage penalty on lower-income taxpayers, see Anne L. Alstott, The Earned Income Tax Credit and the Limitations on Tax-Based Welfare Reform, 108 Harv. L. Rev. 533, 559-64 (1995) (demonstrating tax penalty inherent in the Earned Income Tax Credit). 
In contrast, there are no specific constraints regarding the distribution of tax changes, and the basic distributional question being addressed is unquestionably a proper one. In changing a tax system whose history-indeed its constitutional status-is grounded in notions of ability to pay, it is obviously important for policymakers to attempt to know the distributional consequences of proposed changes. However, as with the revenue estimates, the basis for congressional evaluation and decisionmaking regarding distributional issues is seriously flawed.

Congressional decisionmaking regarding both the revenue and distributional questions reveals a unitary weakness in the current tax legislative process: Congressional decisionmakers routinely suffer from illusions of precision. Congress today seems to want tax policymaking to turn on simple numerical answers, reminiscent of the supercomputer Deep Thought, who in the science fiction classic, The Hitchhiker's Guide to the Galaxy, revealed that the answer to the "great Question of Life, the Universe and Everything" was "42."16 Armed with mathematical answers to both revenue and distributional questions, tax policymakers routinely eschew the difficulties of exercising judgment to strike an appropriate balance among ambiguous and often conflicting normative goals; in the process, they put aside the massive empirical uncertainties they inevitably face. Instead, they constrain themselves to write laws that conform to misleading or wrongheaded mathematical straightjackets.

This Article deals in some detail with two kinds of such numbersdistributional and revenue numbers-and how they are used and misused in the tax legislative process. ${ }^{17}$ I shall consider the distributional and revenue issues in turn. I conclude that current practices of relying solely on five- or ten-year annual revenue estimates and of fashioning tax legislation to achieve a particular result in a distribution table create an illusion of precision when such precision is impossible. In reaching this

16. Douglas Adams, The Hitchhiker's Guide to the Galaxy 179-80 (1979).

17. Tax policymaking is not unique in the political or legislative process for its misuse of numerical constructs. It has become well known, for example, that the consumer price index (CPI) tends to overstate the impact of inflation on purchasing power, but inflation adjustments tied to CPI changes can nevertheless be found in much legislation, including Social Security benefits, welfare payments, and budget rules. Similarly, the main advantage of the current poverty level measure is its consistency over time. It probably was not a very good measure of poverty when first constructed in the 1940 s and surely is inadequate and misleading today, yet legislation is routinely advanced targeting subsidies to some percentage of this poverty level. In 1994, for example, Democrats and Republicans both linked government subsidies for health insurance to the relationship of a family's income to the poverty level. See Senate, House Democratic Bills at a Glance, Reuters, Aug. 9, 1994, available in LEXIS, News Library, Curnws File; U.S. Senate Republicans Unveil Their Own Health, Reuters, Sept. 15, 1993, available in LEXIS, News Library, Curnws File.

Likewise, each year the Internal Revenue Service (IRS) publishes the amount of the so-called "tax gap" - the amount of under-reported taxes from legal sources of incomewhich is now estimated to be over $\$ 100$ billion. One cannot help but wonder why, if the IRS knows with such precision how much in taxes is being under-reported, it does not simply collect some of this money. 
conclusion, I do not mean to embrace an easy attack on the theoretical difficulties and limitations of data in order to conclude that nothing of any import can or should be said. That would be palpably false. There is much we know about the likely winners and losers from changes in tax policy. Decisionmakers need such information and are entitled to share in this knowledge. But current illusions of precision should be abandoned.

This Article argues that the tax policymaking process would be far better served by abandoning altogether the current practice of having staffs routinely construct distributional tables for Congress and the Adininistration to consider while legislation is pending in the Congress. Instead, decisionmakers generally should be given qualitative information about how the proposed amendinents to the law will likely affect the size and distribution of people's after-tax incomes. Quantitative estimates of the effects of tax legislation on the distribution of taxes should be produced periodically by the relevant tax staffs as background information for decisionmakers and should take into account the variations in approaches to specific issues that this Article discusses in detail. With regard to revenue estimates, greater attention should be given to long-term and overall revenue consequences of legislation to eliminate the current practice of structuring legislation to inaximize revenue gains or minimize revenue losses within the budget period. In addition, the reliability-or lack thereofof these estimates should be identified for policymakers, for example, by providing a range of likely outcomes. In the conclusion to this Article, I provide examples of the kinds of information that should be presented to decisionmakers and describe why I believe such a change would improve the tax decisionmaking process.

\section{The Relevant Staffs}

Policymakers in the Congress and Administration routinely receive two sets of tables that recently have been outcome-determinative in the legislative drafting process: revenue tables, which estimate anticipated annual revenue effects of each proposed change over the following five or ten years, and distributional tables, which purport to reflect the anticipated distribution among income classes of proposed changes in the tax law. The computer revolution permits new tables reflecting new policy options to be generated in a matter of hours. When different political parties are in control at the White House and in Congress, the political contest over the "relevant facts" sometimes results in dueling tables froin the Adıninistrative and Congressional staffs. In recent years, as legislation has progressed through the lawinaking process, these revenue tables have often dominated legislative decisionmaking and the distributional tables have becoine Congress's sole basis for evaluating the vertical equity of proposed legislation.

Generally, politicians get their revenue and tax distributional information from three staffs of experts: the staffs of the Joint Committee on 
Taxation (JCT), the Congressional Budget Office (CBO), and the Treasury's Office of Tax Analysis (OTA). JCT, which was established in 1926, has long served as the principal technical staff to the tax-writing committees of the Congress. For many years, JCT was the only substantive tax staff for these committees, but today both the House Ways and Means Committee and the Senate Finance Committee have majority and minority staffs which specialize in tax matters. JCT is the official scorekeeper the Congress for revenue estimates; it also provides the tax-writing committees with tables reflecting its estimates of distributional changes of pending legislation.

The Joint Committee on Taxation has long been extremely influential in the tax legislative process. Its chiefs of staff have typically enjoyed great respect among Congressional members of both political parties. Only three people served as JCT Chief of Staff during its first fifty years from 1926 to 1976 . Since the late 1970s, however, staff proliferation and turnover has diffused JCT's power and influence. JCT has had six different staff chiefs during the period 1977-1994. The 1970s marked the beginning of a great expansion of the number of people, particularly congressional staff, involved in the tax lawmaking process. Tax specialists began taking positions as minority and majority staff members of the taxwriting committees, diminishing substantially the influence of the staff of the Joint Committee on Taxation.

In 1974, Congress completely revised its processes for enacting budget legislation. Budget committees were established in both the House and Senate, and the Congressional Budget Office was created to serve the new budget committees. Each year these committees propose a budget resolution, which then is taken up by the House and Senate and ultimately combined into a joint budget resolution. This joint resolution specifies the amounts to be spent for various categories of expenditures and the amount of revenue to be raised; the resolution also instructs the tax-writing committees to produce legislation meeting certain revenue targets. Both the House Ways and Means Committee and the Senate Finance Committee are bound to comply with these resolutions. If a legislative proposal fails to do so, any member can raise a point of order in objection, and such objections can only be overridden by special voting rules. ${ }^{18}$

The Congressional Budget Office is a creature of the 1974 Budget Act. $\mathrm{CBO}$ reports to the Budget Committees of the House and Senate. ${ }^{19}$ CBO is the official scorekeeper for Congress on spending and technical budget issues - a recent example was the federal budgetary treatment of

18. In the 1980 s and $1990 \mathrm{~s}$, these budget rules were further constrained by the Gramm-Rudman-Hollings legislation, see Public Debt Limit-Balanced Budget and Emergency Deficit Control Act of 1985, Pub. L. No. 99-177, 99 Stat. 1037 (1985), and the Budget Enforcement Acts, see OBRA 90, supra note 5 and OBRA 93, supra note 6.

19. See Congressional Budget and Impoundment Control Act of 1974, Pub. L. No. 93344 , §§ 201-202, 88 Stat. 297, 302-05 (1974). 
various health reform proposals-and $\mathrm{CBO}$ often publishes analyses of recently enacted tax legislation or issues pending before the Congress. $\mathrm{CBO}$ is responsible for estimating federal government spending, changes in spending in connection with appropriations and budget legislation, and total annual receipts of the federal government for each year of the five- or ten-year budget period. However, it does not estimate the revenue consequences of specific legislative tax proposals, nor does it normally produce distributional tables for members of Congress to consider during legislative deliberations. Nevertheless, in connection with the 1990 Budget Act negotiations, CBO did produce distributional tables of legislative proposals, presumably at the request of the Democratic Congressional leadership or chairmen of the House and Senate Budget committees.

In combination, JCT and $\mathrm{CBO}$ estimates of spending, receipts, and revenues are critical in the legislative process. Under both the House and the Senate rules, these estimates determine whether proposed legislation violates the rules of the governing Budget Act, thereby becoming potentially subject to a point of order. ${ }^{20}$ If a budget point of order applies, supermajority votes-for example, sixty of the one hundred Senatorsare necessary to waive or override the point of order and take up the legislation on its merits.

Since the beginning of the federal income tax in 1913, the Secretary of the Treasury has had at least one economist whose principal function was to provide analysis and advice on tax policy matters. Over time, the responsibility for tax policy advice within the Treasury Department has come to reside in the Office of the Assistant Secretary for Tax Policy. Both the economists and lawyers in that office are involved in legislative analysis, with the lawyers principally responsible for drafting legislation and writing regulations and the economists responsible for analyses of the economic aspects of tax policy proposals. These economists comprise the Treasury's Office of Tax Analysis (OTA), which reports to the Secretary of Treasury through the Assistant Secretary for Tax Policy. OTA is the Administration's official estimator of total budget receipts and anticipated revenue effects of proposed legislative changes. OTA also routinely provides the Administration's decisionmakers with distributional and analytical analyses of tax proposals and legislation. Sometimes OTA's distributional tables are used by members of Congress during the formulation of legislation, but the JCT tables have dominated the legislative process in recent years. ${ }^{21}$ OTA's revenue estimates, on the other hand, play a critical role in the legislative process, since under the 1990 and 1993 Budget Acts the Administration's official revenue estimates-not those of CBO

20. See OBRA 90, supra note 5, at $\$ 13207$ (points of order); id. at $\S 13214$ ("Byrd rule" allowing points of order to be raised against extraneous matters in budget reconcilation bills).

21. For example, JCT distribution tables were the only tables used by Congressional decisionmakers in both the 1990 and 1993 legislation. 
or JCT - determine whether automatic spending reductions, so-called sequestration, take effect.22

The Office of Management and Budget (OMB) is the executive branch's counterpart to the CBO. OMB is responsible for estimating spending and is nominally responsible for estimating total receipts and revenue effects of legislation, but the substance of these latter two tasks is assigned to OTA. OMB simply takes OTA estimates of receipts and revenues and incorporates them into OMB official publications and estimates. Unlike CBO, OMB does not perform its own analyses of tax legislation or tax policy proposals.

As this brief review suggests, both OTA and JCT revenue estimates are of critical importance in the legislative process, with JCT estimates determining whether a congressional point of order is permissible and OTA estimates determining whether sequestration is required. JCT distributional tables have recently been most significant. Data produced by these staffs are often reconfigured, explained, and sometimes contested by other congressional staffs, the media, and private analysts. Recently, JCT has revised certain important aspects of its standard distributional analyses. ${ }^{23}$ Staff members from both OTA and CBO have also outlined their (somewhat different) methodologies. ${ }^{24}$

\section{Distributional TABles}

The distributional data produced by these three government staffs are of two general types, only one of which is particularly troublesome. First, each staff from time to time publishes distributional data as part of an analysis of various kinds of tax issues. For example, CBO frequently publishes analyses of changes over time in the distribution of after-tax incomes, the distributional impact of recently-enacted tax legislation, of the tax system as a whole, or of specific tax provisions. Two recent examples are its analyses of the Revenue Act of 1993 and the exclusion from

22. See OBRA 90, supra note 5 , at $\S 13101$; OBRA 93, supra note 6 , at $\S 14003$.

23. See Staff of the Joint Comm. on Taxation, 103d Cong., 1st Sess., Methodology and Issues in Measuring Changes in the Distribution of Tax Burdens (Comm. Print 1993) [hereinafter JCT, Measuring Tax Burdens 1993]; Thomas A. Barthold \& William Jack, Joint Committee on Taxation, Summary of the Joint Committee on Taxation Distribution Methodology passim (1993).

24. See Distributional Analysis of Tax Policy (David F. Bradford, American Enterprise Institute ed, forthcoming September 1995); Susan C. Nelson, Family Economic Income and Other Income Concepts Used in Analyzing Tax Reform, Tax Notes Today, Jan. 28, 1988, available in LEXIS, Fedtax Library, Taxtxt File; Richard A. Kasten, Congressional Budget Office, CBO's Method for Simulating the Distribution of Combined Federal Taxes Using Census, Tax-Return, and Expenditure Microdata, State Tax Notes, Nov. 19, 1991, available in LEXIS, Sttax Library, Stn File.

Private and academic economists have also demonstrated great interest in the distribution of taxes. See, e.g., Don Fullerton \& Diane L. Rogers, Who Bears the Lifetime Tax Burden? (1993); Joseph A. Pechman, Who Paid the Taxes, 1966-1985? (1985); Joseph A. Pechman \& Benjamin A. Okner, Who Bears the Tax Burden? (1974). 
income of employer-provided health benefits. ${ }^{25}$ Likewise, the Treasury annually publishes an analysis of taxes paid by higher-income taxpayers. ${ }^{26}$ While these documents may have more force in the legislative arena than private or academic analyses of distributional issues, they are essentially designed to serve similar functions: namely, to provide ongoing information and analysis of significant tax policy issues.

A second and more problematic use of distributional tables is that by policymakers during legislative drafting and deliberation. When tax legislation is being considered by the committees, distributional tables are reviewed by policymakers who are deliberating and deciding the shape and detail of legislation being considered. ${ }^{27}$ As tentative decisions are made, new distributional tables reflecting the tentative new decisions are often produced, typically by JCT but sometimes by OTA as well. To serve this function, these tables must be produced and revised quickly, often in a matter of hours. Members of Congress are not especially responsive to staff requests for additional time for analysis. For example, in both 1990 and 1993, important legislative decisions were taken to achieve certain results in JCT's distributional tables (as well as to meet specific revenue targets), and the 1986 Tax Reform Act was constrained to be distributionally (as well as revenue) neutral. ${ }^{28}$ This means that as legislation is being crafted, changes are made in the specifics of the legislation, or proposals are added or dropped, to make the distributional tables "come out right." As Mickey Kaus lias put it, "distributional charts . . . have elevated the 'details of the counting-house' into the sine qua non of justice and 'fairness.' "29

Given the limits of time, inadequacies of data, and important theoretical conundrums, what kind of data should be provided by staffs to best

25. See Congressional Budget Office, An Economic Analysis of the Revenue Provisions of OBRA-93 (1994); Congressional Budget Office, An Analysis of the Tax Exclusion of Employer-Provided Health Benefits (1994).

26. See, e.g., Statistics of Income Division, Internal Revenue Service, Individual Income Tax Returns 1988, 67-92 (1991).

27. For an example of such a table, see Table 1, infra at 628 .

28. In the presence of ambiguity, politicians will, of course, often also want to know how most effectively to respond to factual claims by their political adversaries. Given the nature of my enterprise here, I can simply assume that each staff regards its mission in each of these contexts as providing the best information possible to the politicians who have decisionmaking responsibilities. I can also simply assume here that political decisionmakers want to be as well informed as possible in order to decide whether to support or oppose alternative policies. This assumption provides the best context in which to frame the issues to be discussed in this paper, although we are not obliged to be pollyannish in evaluating the judgments I offer here. We all know that there are times when immediate political advantage is of greater import to a politician than "good" policy, although we might have differing views about the frequency of those occasions. We can also admit that there may be moments when the purveyor of the information might be pursuing her own policy agenda, rather than simply informing the decisionmaker to the best of her abilities. But let us put aside for now questions of potential misuse of information or abuse of position.

29. Mickey Kaus, The End of Equality 22 (1992). 
inform decisionmakers? Are the distributional tables of the sort now routinely provided the most appropriate kind of information? Should the politicians' distributional questions be answered in the manner economists or moral philosophers regard as the best? In these circumstances, where representatives selected through democratic processes are imposing social obligations on the citizenry, how, if at all, should the public's intuitions and ability to understand complex information constrain the process? If this Article does nothing more, it should prove these questions to be difficult enough.

I shall approach this issue by examining limitations inherent in the staffs' ability to provide precise noncontroversial answers to distributional questions. To begin this inquiry, I briefly examine a somewhat old-fashioned theoretical economic consensus about how best to illuminate distributional issues. This inquiry should illustrate some aspects of distribution that are buried in seemingly precise summary measures. For the uninitiated, this should put more flesh on the distributional issue itself. I then explore some significant areas where the different staffs disagree over answers to specific questions necessary to construct distributional tables. Then I describe areas of staff agreement where the consensus hides potentially important information.

\section{A. Impossible Goals and Impractical Tasks}

Thoughtful economists have long known that it is impossible to assess precisely the effects of governinent policies on the distribution of income and wealth. In his excellent public finance treatise, Carl Shoup describes the problem:

To say, for example, that households with before-tax incomes between $\$ 2,000$ and $\$ 5,000$ pay 12 percent of that income in taxes, directly and indirectly, is to make a statement that is without significance because it is conceptually invalid. It is conceptually invalid because it postulates, for implicit comparison, a state of affairs in which there are no taxes whatever, and no government borrowing or creation of new money, hence impliedly no government services, not even of the minimum type and amount necessary to assure existence of the society. ... [This] objection is conclusive. ${ }^{30}$

Shoup's basic point is quite telling. The most interesting questions-the overall effects of government action (or even of one level of government, say the federal government) on the distribution of income-are impossible to evaluate, even in principle. This is because the point for comparison, namely, the distribution of income absent any government, is unknowable, indeed unimaginable. But attempting to quantify this impossible answer is the daily bread of the tax policy staffs of the Congress and the Treasury. The first two columns of the standard distri-

30. Carl S. Shoup, Public Finance 577-78 (1969). 
butional tables prepared routinely by $\mathrm{CBO}$, JCT and OTA purport to show the amount of taxes and average tax rates paid currently by people at different levels of income. ${ }^{31}$ Indeed, virtually everyone who analyzes the distribution of tax burdens and estimates the effects of proposed changes begins at this same "conceptually invalid" place-with an estimate of the distribution of the existing tax burden. The fundamental questions that are raised by these estimates are simply never asked; the extent to which government policies have affected the amount of income earned by the people who are being evaluated in such tables is buried, as it must be. This means that the least controversial aspect of the table-the snapshot of conditions as they supposedly exist before any policy changes are considered-is itself constructed on quicksand.

Of course, it is neither "conceptually invalid" nor without meaning to inquire whether a change in tax (or other government) policy is likely to make the distribution of after-tax income or wealth more equal or more unequal. ${ }^{32}$ To the contrary, this question is frequently essential and often answerable, at least in a general way, with a high degree of confidence. For example, it should not be controversial to say that a shift from a progressive personal income tax to a flat rate consumption tax would tend to make the after-tax distribution of income more unequal. But it is the way in which answers to such questions are presented to decisionmakers for evaluating changes in policy that is troublesome.

\section{B. Where Has Gini Gone?}

Traditionally, economists agreed about the proper way, at least as a matter of theory, to measure the distributional effects of changes in the tax law: the magnitude of each unit's after-tax income is determined before and after the revision of the tax law and the results are compared. To determine whether a tax change increased or reduced income inequality and to depict these effects graphically, economists typically have constructed two Lorenz curves ${ }^{33}$-one before the change, the other after-then compared their Gini coefficients. ${ }^{34}$

A Lorenz curve arranges the population from the poorest to the richest along the horizontal axis and the percentages of income enjoyed by various percentages of the population along the vertical axis. Zero percent of the population will always be shown as having zero percent of the income and $100 \%$ of the population will always have $100 \%$ of the income. In this construction, if everyone has the same income the Lorenz curve will be a diagonal straight line. Whenever the poor have proportionally less income than the rich-the common state of affairs-the Lorenz curve stretches below the diagonal with its slope typically rising as one

31. See Table 1 , infra at 628.

32. See Shoup, supra note 30 , at 578-79.

33. See M.O. Lorenz, Methods of Measuring Concentration of Wealth, 9 Publications of the Am. Stat. Ass'n 209 (1905).

34. See Corrado Gini, Variabilitá e Mutabilitaá [Variability and Mutability] (1912). 
moves from poorer to richer segments of the population. Figure 1 depicts a typical Lorenz curve:

\section{FIGURE 1}

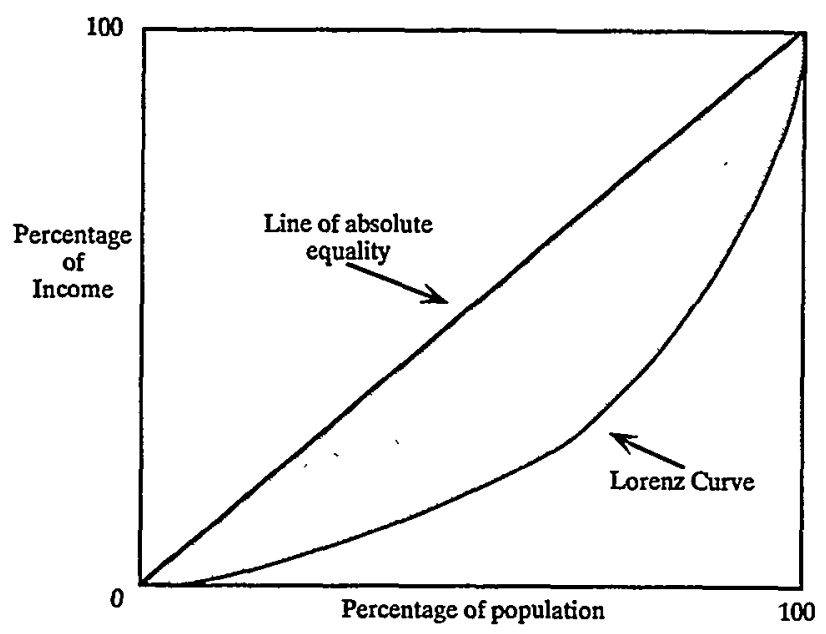

If the Lorenz curve after a tax revision lies entirely between the diagonal and the pre-enactment Lorenz curve, the tax change will have made the distribution of income relatively more equal. With the introduction of an effective progressive income tax, which imposes a higher share of taxes as pre-tax income rises, post-tax income would be more equally distributed than pre-tax income, presumably for every segment of the population (assuming that the tax does not result in a reorganization of the orderings of pre-tax income levels). Such an outcome is shown in Figure 2.

Figure 2

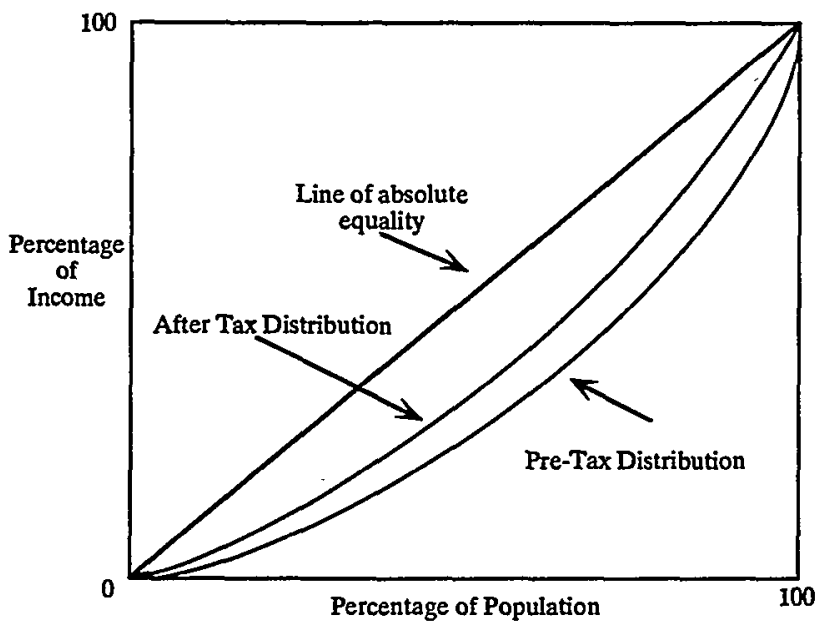


In contrast, a proportional income tax should preserve relative differences in pre-tax income, resulting in an unchanged Lorenz curve and, on this criterion at least, a distributionally neutral outcome.

Of course, comparing Lorenz curves tells nothing about absolute levels of income, only relative shares. There is no way to tell from these curves alone how much lower (or higher) the levels of income are before and after the tax change. Moreover, a universally equality-enhancing result of the sort depicted in Figure 2 is by no means inevitable from a change in policy. In addition, if the Lorenz curve after the change crosses the one before the change, simply eyeballing the graphs will tell little. What seems to be needed is some index number to identify whether relative inequality has been increased or decreased. This is where Gini came in.

A Gini coefficient quantifies how far an income distribution is from the diagonal (the equal distribution of incomes) by measuring the area between the diagonal and a given Lorenz curve as a fraction of the total area under the diagonal. This fraction will always be between zero and one, with zero representing an equal distribution (a Lorenz curve along the diagonal) and one representing maximum inequality. Lower Gini coefficients signal more equal distributions of incoine. Since a Gini coefficient can always be calculated for any Lorenz curve, Gini permits a complete ranking of income distributions regardless of the shapes or intersections of the Lorenz curves being compared. This comprehensive ordering quality is useful and no doubt accounts for some substantial measure of Gini's longstanding popularity. Any transfer from a richer to a poorer person will always reduce the value of the Gini coefficient. Moreover, the Gini coefficient will remain unchanged if everyone's income is lowered (or raised) in the same proportion. Thus, a progressive income tax would lower the Gini coefficient and a proportional income tax would leave it unchanged. ${ }^{35}$

35. Gini coefficients and other measures of income inequality can be used in a variety of ways. The text, for example, discusses Lorenz curves and Gini coefficients in comparing pre-tax and post-tax Ginis and also in comparing post-tax Ginis before and after a change in the tax law. Changes in tax laws may produce changes in pre-tax incomes, which, in principle at least, might be captured by comparing pre-tax Ginis before and after the change, although observed changes in pre-tax income may be due to a variety of other factors. For example, relatively greater incomes earned by educated people clearly made pre-tax distribution of income more unequal during the 1980s. Changes in tax law also might change the relationship of pre-tax and post-tax income curves. Quantifying this effect is somewhat more difficult; one way to do so would be to examine the difference between pre-tax minus post-tax Ginis before the change and pre-tax minus post-tax Gini's after the change. Keeping all of this straight requires close scrutiny, and politicians often blur the various elements. Throughout the $1980 \mathrm{~s}$, Repuhlicans, for example, often pointed to the increased share of income taxes paid by higher-income taxpayers during the period following the 1981 Tax Act, but this could have occurred as a result of higher shares of pretax income, even if the tax law had become less progressive. The relative shares of pre-tax income might or might not have been connected to the tax change. Some would argue that pre-tax incomes of upper-income taxpayers grew because people responded to lower 
However, the ethical and normative force of the Gini coefficient has been questioned. ${ }^{36}$ Although transfers from richer to poorer people will always reduce the Gini coefficient, changes in Gini coefficients turn on the number of people between the income levels of the redistribution without regard to the differing levels of income. ${ }^{37}$ The important point of these criticisms has been to expand the numbers and kinds of measures of inequality in the literature, ${ }^{38}$ to demonstrate the normative complexity of the concept of inequality, and to suggest the controversy-or, on the contrary, the closed-mindedness-of relying on any single measure of inequality. ${ }^{39}$ Nevertheless, economic treatments of income distribution issues continue to accord Gini a prominent place..$^{40}$

I have been unable to find any occasion on which OTA or JCT has published Gini coefficients for proposed or enacted tax laws. Perhaps they have rejected this idea because of the difficulties with Gini noted above. Another possible reason-that neither the populace nor their elected representatives would have any idea what a Gini coefficient is or means-while perhaps true, seems unlikely. These staffs' regular business is translating difficult and obscure legal and economic concepts to make them understandable to politicians, and Gini coefficients or other such measures of the effects of tax changes on the after-tax distribution of income do not seem to pose any unique problems in this regard. Indeed, the $\mathrm{CBO}$ has published studies that include estimates of Gini coefficients to evaluate the relative progressivity of legislation of 1977,1981 , and 1984. 41 This is not CBO's standard procedure for analyzing the distribution of tax changes, however. In its 1992 Economic Report of the President, the Council of Economic Advisors, while emphasizing that they present an incomplete picture, also set forth Gini coefficients of U.S. fam-

tax rates by working harder and foregoing tax-sheltered income. Others would contend that higher returns to education prompted the increase and that upper-income people received more pay for the same work as the economy became more global and less regulated.

36. See, e.g., Amartya Sen, On Economic Inequality 31-39 (1973); Anthony B. Atkinson, On the Measurement of Inequality, $2 \mathrm{~J}$. Econ. Theory 244, 261-62 (1970).

37. See Sen, supra note 36 , at $32-34$.

38. See Atkinson, supra note 36 , at 257 (describing social welfare function approach).

39. See Sen, supra note 36.

40. See, e.g., Alissa Goodman \& Steven Webb, For Richer, For Poorer: The Changing Distribution of Income in the United Kingdom, 1961-1991 (Institute for Fiscal Studies Commentary No. 42) (1994) (using various measures, including Gini coefficients, to describe changes in overall income inequality and living standards in the United Kingdom between 1961 and 1991); Peter J. Lambert, The Distribution and Redistribution of Income: A Mathematical Analysis (forthcoming Oct. 1995); J. Richard Aronson \& Peter J. Lambert, Decomposing the Gini Coefficient to Reveal the Vertical, Horizontal and Reranking Effects of Income Taxation, 47 Nat'l Tax J. 273 (1994) (disaggregating Gini coefficients to determine effect of taxes on unequal treatment of people similarly situated, differential treatment of people differently situated, and effect in making ranking of people different post-tax than it was pre-tax).

41. See Congressional Budget Office, The Changing Distribution of Federal Taxes: 1975-1990 (1987). 
ily income for the period 1947-1991. The report showed relatively gradual increases in Gini-less equality of incomes-during the period 1968-1990.42 Such shifts in the distribution of income over time are, of course, only partly due to changes in the tax law; market forces and other government actions may be far more important. ${ }^{43}$

It is well beyond my task here to rehearse or comment on the specific debates that have occurred. Rather, my purposes have been principally two: First, to introduce uninitiated readers to the subject of Lorenz curves and Gini coefficients in order to illustrate some of the issues and difficulties that can lie behind what may appear to be precise comparisons of different income distributions. Each of the measures used makes controversial choices about what information to include and about how to depict comparisons or changes over time. Second, this discussion demonstrates that the effects of relevant government policies on the distribution of after-tax income have historically concerned economists and others who have analyzed income distributional issues outside the legislative arena. Ultimately, it is the impact of legislation on the distribution of after-tax incomes that should be of concern in analyzing the distributional consequences of legislative changes, although the effects of legislation on after-tax income will often take considerable time to occur, and, in many cases, will be unknowable. Regardless of the difficulties with the mechanisms for quantifying and comparing different policy proposals, however, the focus on after-tax incomes remains an extremely useful baseline for evaluating the questions I raise here. As will become clear in the following section, however, distributional tables, particularly those prepared by JCT, often stray rather far from even attempting to answer this question. I am confident, however, that policymakers often do not realize that the distributional tables they are using address quite a different question.

\section{Staff Disagreements in Constructing Distributional Tables}

1. Distributing Changes in Taxes vs. Changes in "Burden". - Since virtually every normative measure (including Gini coefficients and Lorenz curves) of changes in income distributions expected from or due to changes in government policies is based upon comparisons of after-tax incomes, it is only natural to assume that distributional tables reflect the staffs' best estimates of who will bear tax (revenue) increases or pay reduced taxes due to tax law changes. Although this assumption is generally true for OTA, JCT and CBO distribute the changes in tax revenue that would result if no one changed behavior in response to the change in the tax law.

42. See Council of Economic Advisors, The Economic Report of the President, 123-34 (1992); see also Goodman \& Webb, supra note 40, at 11-12 (setting forth Gini coefficients showing sustained period of increasing income inequality in United Kingdom during the period 1977-1991).

43. See Sen, supra note 36 , at 22 . 
To understand JCT and CBO methodology-which has recently been and may well continue to be of great importance in the political process-it is necessary to understand how the JCT distributional analysis differs from its estimates of revenue effects of changes in tax policy. ${ }^{44}$ As I discuss further in Part III, in estimating the revenue effects of tax changes, JCT and CBO take into account their predictions of the behavioral responses of people affected by the tax (including consumers, producers, and suppliers of capital and labor). For both distributional and revenue estimates, the three agencies hold constant major macroeconomic variables (such as the level of GDP, aggregate cash and non-cash wages, corporate profits, interest rates, and assumptions of inflation).$^{45} \mathrm{It}$ is useful to think of these revenue calculations as occurring in two stages: JCT, CBO, and OTA first estimate the revenue gain or loss that would occur if behavior were unchanged-the cognoscenti call this the "static revenue change" - and then estimate any offset to the static revenue estimate due to peoples' behavioral responses.

In constructing their distributional tables, however, JCT and CBO are interested in the distribution of changes in economic well-beingwhich they label tax "burdens"-rather than changes in taxes paid, and use only the static revenue change in measuring the change in tax burdens to be distributed across income classes. JCT and CBO only distribute the static line in estimating changes in economic burden. JCT and $\mathrm{CBO}$ choose to ignore behavioral effects, justifying their exclusion as necessary "to present meaningful estimates of the change in well-being." 46 Thus, voluntary behavioral shifts and any additional taxes which accompany them are ignored by JCT and $\mathrm{CBO}$ in producing tables reflecting changes in the economic burdens of tax legislation.

The decision of JCT and $\mathrm{CBO}$ to use the static revenue estimate as a measure of the changes in economic burden is based on a straightforward argument. To the extent that increases in the actual taxes paid are due to behavioral changes, such as a voluntary increase in the behavior

44. See JCT, Measuring Tax Burdens 1993, supra note 23, at 26-29.

45. The relevant macroeconomic variables are given to JCT by $\mathrm{CBO}$, which uses them in its general budget estimates. OTA follows the same practice for revenue estimates, except that the macroeconomic variables are supplied by the so-called Troika (the Council of Economic Advisers, the Office of Management and Budget, and Treasury's Assistant Secretary for Economic Policy). Thus, for example, in estimating the revenue effects of the income tax rate increases enacted in 1993, JCT took into account likely shifts of investments of high-income people to purchases of tax-exempt bonds or to other taxfavored investments, for example, by substituting low dividend, high capital gain stocks for high dividend stocks, but it did not take into account the macroeconomic impact on GDP or total wages. See Staff of Joint Comm. on Taxation, 102d Cong., 2d Sess., Discussion of Revenue Estimation Methodology and Process 6-11 (Comm. Print 1992) [hereinafter JCT, Revenue Estimation 1992]. Likewise, in estimating the revenue effects from President Clinton's 1994 proposal for a one dollar increase in the tobacco tax, the JCT and OTA took into account their estimates of how many people would quit or reduce smoking in response to the tax increase.

46. JCT, Measuring Tax Burdens 1993, supra note 23, at 28-29. 
that is to be taxed, the voluntary increases in the taxes paid inust have been at least equaled or exceeded by some other benefit; otherwise, the change in behavior would not have occurred. In the case of decreases in tax rates, voluntary increases in the behavior subject to the tax reduction are therefore ignored. Likewise, in the case of an increase in tax rates, offsetting reductions in revenue due to behavioral responses reflect changes that taxpayers would have preferred not to have made absent the tax increase. This means that, in such cases, the static revenue estimate overstates the change in burden, and the dynamic revenue estimate understates the change in burden.

As JCT explicitly acknowledges, the decision to estimate burdens using the static revenue estimate has certain systematic effects; it "overestimates the loss of economic well-being due to a tax increase, and understates the progressive improvement in economic well-being due to a tax reduction." 47 In other words, when tax decreases are translated into economists' measures of "welfare gains and losses," the static revenue loss represents a minimum of the "welfare gain" because the behavioral changes that are ignored would occur only if they also added to the person's welfare; in contrast, static revenue gains from tax increases typically reflect the maximum welfare loss, because people's behavioral responses will be undertaken for the purpose of reducing the welfare losses that would otherwise occur. If one regards the key distributional question as the effect of the tax change on the distribution of after-tax income, JCT's practice of distributing static revenue change overstates the burden of tax increases and understates the effect on welfare of tax reductions. 48 Notwithstanding the measurement difficulties, the JCT distribution methodology is intended to be an easy and feasible approximation of changes in "economic well-bemg." In some cases, a proper measurement of burdens will correlate to changes in after-tax income, but the benefits that occur due to voluntary changes in behavior will often be in psychological well-being-so-called psychic income-or some other nonmonetary benefit which does not connect to after-tax income.

In contrast to both JCT and CBO, OTA's distribution tables reflect for each income class its best estimates of the actual changes in revenues that it expects to result from the change in law, taking into account both the static revenue estimate and predicted behavioral responses. ${ }^{49}$ OTA, therefore, is measuring changes in actual taxes paid and if this information is combined with changes in pre-tax income, a straightforward determination of changes in after-tax income becomes possible.

This difference in methodology is extremely important but not well understood by policymakers. Indeed, while distributing changes in "bur-

47. Id.

48. Each of the observations in this paragraph assumes no changes in macroeconomic variables or, following JCT and OTA common practice, ignores such changes.

49. See James R. Nunns, U.S. Dept. of Treasury, OTA's Methodology for Distributional Analysis 3 (1993). 
den" rather than changes in taxes has been a long-standing practice of JCT, at least with respect to changes in capital gains taxes, it has only recently described and defended this process. .50 In an important public service, JCT has recently published lengthy pamphlets detailing the methodology it uses in producing distributional tables and in making revenue estimates. ${ }^{51}$ In 1993, JCT also changed the heading on its tax distributional tables so that instead of showing "changes in taxes," the third and fourth columns of the tables now show "changes in tax burden." The table that follows provides a typical example of a JCT distributional table, in this case the JCT Summary of the Omnibus Budget Reconciliation Act of 1993 which reflects JCT's estimates of the distributional effects of that legislation: ${ }^{52}$

TABLE 1

Distributional Effects of the Revenue Provisions Contained in the Ominibus Budget Reconciliation Act of 1993 as Passed by Congress

\begin{tabular}{ccccc}
$\begin{array}{c}\text { Expanded Income } \\
\text { Class }\end{array}$ & $\begin{array}{c}\text { Present-Law } \\
\text { Federal } \\
\text { Taxes } \\
\text { (Billions) }\end{array}$ & $\begin{array}{c}\text { Present-Law } \\
\text { Avg. Tax } \\
\text { Rate } \\
\text { (Percent) }\end{array}$ & $\begin{array}{c}\text { Proposed } \\
\text { cliange in Tax } \\
\text { Burden } \\
\text { (Millions) }\end{array}$ & $\begin{array}{c}\text { Burden } \\
\text { Change as a } \\
\text { Share of } \\
\text { Income } \\
\text { (Percent) }\end{array}$ \\
\hline Less than $\$ 10,000$ & 9 & $10.4 \%$ & -1.152 & $-1.28 \%$ \\
$\$ 10,000$ to $\$ 20,000$ & 39 & $11.9 \%$ & -993 & $-0.30 \%$ \\
$\$ 20,000$ to $\$ 30,000$ & 72 & $17.0 \%$ & 94 & $0.02 \%$ \\
$\$ 30,000$ to $\$ 40,000$ & 86 & $19.1 \%$ & 949 & $0.21 \%$ \\
$\$ 40,000$ to $\$ 50,000$ & 93 & $20.9 \%$ & 1,271 & $0.29 \%$ \\
$\$ 50,000$ to $\$ 75,000$ & 201 & $22.3 \%$ & 3,517 & $0.39 \%$ \\
$\$ 75,000$ to $\$ 100,000$ & 120 & $24.6 \%$ & 2,653 & $0.54 \%$ \\
$\$ 100,000$ to $\$ 200,000$ & 142 & $26.6 \%$ & 4,598 & $0.86 \%$ \\
$\$ 200,000$ and over & 168 & $30.2 \%$ & 29,683 & $5.39 \%$ \\
\hline
\end{tabular}

Total,

all Taxpayers

(Notes 1, 2 and 3 are omitted)

4. Includes all revenue provisions except: Individual and corporate estimated tax changes, information reporting for discharge of indebtedness, targeted jobs credit, capital gains incentives, provisions affecting qualified pension plans, mortgage revenue bonds, low-income housing credit, luxury tax provisions, excise tax on diesel fuel used on noncommercial motorboats, empowerment zones and enterprise communities, vaccine excise tax, GSO and FUTA extensions, transfer of Federal Reserve funds, deduc-

50. See JCT, Measuring Tax Burdens 1993, supra note 23, at 28-29; Staff of Joint Committee on Taxation, 101st Cong., 2d Sess., Explanation of Methodology Used to Estimate Proposals Affecting the Taxation of Income from Capital Gains 46-47 (Comm. Print 1990) (dicussing Bush Aministration 1991 budget proposal allowing exclusion of certain capital gains) [hereinafter JCT, Capital Gains 1990].

51. See JCT, Measuring Tax Burdens 1993, supra note 23. See also JCT, Revenue Estimation 1992, supra note 45; JCT, Capital Gains 1990, supra note 50.

52. Given the 1993 Act's provisions, there is very little difference among the JCT, CBO and OTA tables. If a sizeable energy tax had been included, this would not have been the case. 
tion disallowance for certain health plans, orphan drug credit, and diesel fuel compliance.

Source, JCT, August 3, 1993

Note that the first two columns of the JCT table, which show the prechange state of affairs, show the distribution of current taxes, not an estimate of the distribution of the burden of existing taxes. This means that JCT tables contain a mixture of apples and oranges, although the juxtaposition of the figures implies that the columns should be compared.

Thus, for example, in distributing the tax rate increases of the 1993 legislation, the JCT distributional table (Table 1) reflects the increase in taxes that would be paid by high income taxpayers if the tax rate increase induced no behavioral response. To the extent that taxpayers avoid paying additional taxes due to the rate increase by shifting their investment portfolios, for example, toward tax-exempt bonds, or by substituting leisure or non-market work for taxable income, the increase in tax progressivity will be less than policymakers would naturally expect based on the JCT tables. If it were possible to look at the effect of the tax rate increase as it would be looked at retrospectively, say in the year after enactment, the JCT estimates would, ceteris paribus, always show a smaller increase in actual taxes paid than the increased tax burden depicted by its distributional tables. As suggested above, this means that a JCT distributional table for years following enactment will show a distribution of existing taxes (columns 1 and 2 of Table 1 ) that is inherently (and always) inconsistent with its methodology for distributing the "burden" of proposed or enacted tax changes (columns 3 and 4 of Table 1): In other words, although the JCT is estimating changes in burdens rather than changes in after-tax income, it does not and cannot measure existing burdens, only existing taxes paid.

To understand further the implications of this decision, let us look more closely at a few specific cases that recently have been important in the policymaking arena: reductions in capital gains taxes, increases in tobacco taxes, and a recent proposal for a very high tax on certain kinds of ammunition. First, during George Bush's repeated efforts during the period 1989-1992 to reintroduce a lower tax rate for capital gains, the tax policy community focused considerable attention on differences in revenue estimates between OTA and JCT. Beginning with the 1990 Budget Act, however, differences in their distributional methodologies became even more important than differing revenue estimates to the politics of capital gains tax cuts. The capital gains distributions of JCT and OTA differ for a number of reasons, including the fact that Treasury's measure of "family economic income" includes capital gains as they accrue, while JCT's "expanded income" includes gains only when realized, but differences in defining the income classes have relatively minor consequences. ${ }^{53}$ Of far greater, indeed critical, importance is JCT's policy of

53. See infra text accompanying note 69 . 
distributing the burden using static revenue estimates rather than estimates of the change in tax liabilities after taking behavioral changes into account. In contrast, OTA's tables distribute its estimates of changes in actual taxes paid.

In the case of capital gains tax reductions, this practice means that JCT's distribution omits any effect of increased realizations of capital gains due to the reduction of capital gains rates, and its distribution tables depict an overall reduction in tax burden four to six times greater than JCT's own estimates of the reductions in tax collections due to the capital gains tax cut. Since the great bulk of tax savings from a capital gains rate reduction accrues to the upper income classes, any offsetting tax increase on those classes to achieve "distributional neutrality" in JCT's tables-whether through base broadening or rate increases-would have to be four to six times as great as JCT's projected revenue loss of a capital gains tax reduction. This effect is made clear by the JCT pamphlet on capital gains discussing the capital gains tax reduction proposed in President Bush's fiscal year 1991 Budget. JCT estimated a total revenue loss of $\$ 11.4$ billion during the period 1990-1995, with the greatest revenue loss in any one year totaling $\$ 4.3$ billion (in 1992 and 1994). ${ }^{54}$ In its distributional table, however, JCT distributed a one-year tax reduction of $\$ 15.9$ billion to upper income individuals-its static revenue loss-an amount about four times greater than their largest estimated revenue loss for any year. ${ }^{55}$ Figure 3 shows the distribution of JCT's estimated revenue loss-the expected change in actual taxes-compared with its own distribution of the reduction in "tax burden."

54. See JCT, Capital Gains 1990, supra note 50, at 3, 10.

55. See id. at 46 . 
FIGURE 3

Distributional EFFEct OF THE AdMINISTRATION'S

Capital Gains Proposal (1990 INCOME LEVELS

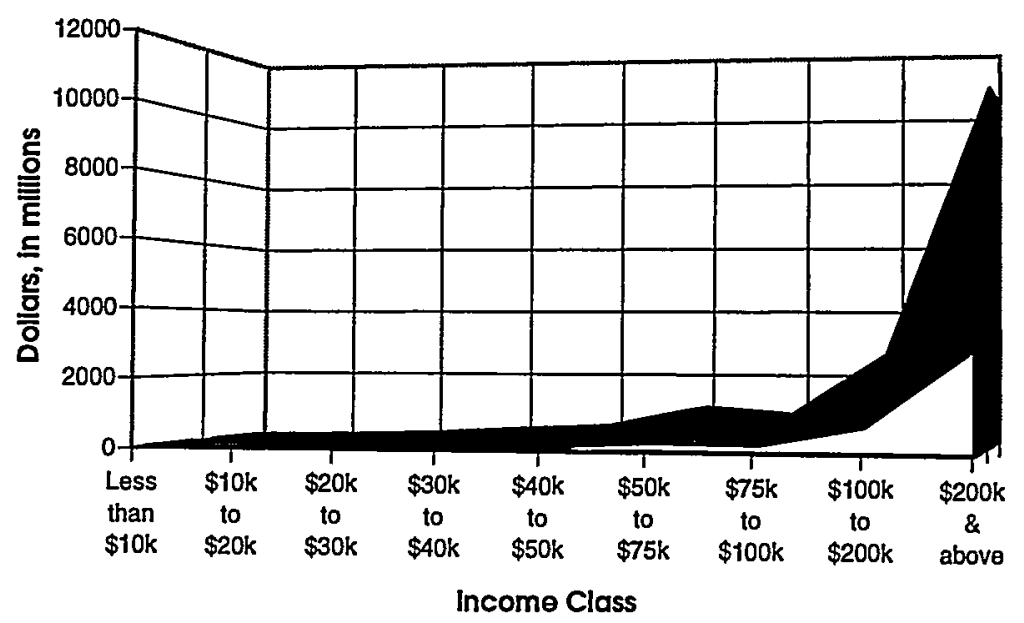

DActual Tax Change DChange in "Burden"

Source: JCT, 1990.

(noles omitted)

These distributions show the alternative revenue increases that would be necessary in each income class to offset a capital gains tax reduction and to achieve "distributional neutrality" in a distributional table depending on whether the actual (estimated) change in taxes or the (estimated) static effect is distributed. Although JCT's methodology for distributing capital gains had not changed, for some reason, the capital gains cuts of the 1993 Act are omitted from JCT's distribution table..$^{56}$

If the capital gains proposal were adopted and JCT's prediction of revenues proved exactly accurate, its distributions of "existing federal taxes" in subsequent years would reflect only the actual change in tax revenues in each income class. Thus, JCT's inethodology of distributing tax proposals is not consistent with its methodology for distributing existing federal taxes, and a capital gains tax cut would appear to distribute very differently looking forward and backward.

Moreover, JCT's use of static revenue losses as a proxy for distributing changes in tax "burdens" creates incentives and opportunities for political gamesmanship. For exainple, in the 1990 Budget Summit Agreement, the inultiplier effect from JCT's inethodology for distribution of capital gains was avoided by substituting a proposal equivalent in present

56. See JCT, Measuring Tax Burdens 1993, supra note 23, at 3 n.4, 29 Table 1. 
value terms to a capital gains reduction on corporate stock-an immediate deduction for a portion of the cost of purchasing corporate stock. ${ }^{57}$ This difference demonstrates the inadequacy of using the static revenue loss as a proxy for "welfare loss." While the welfare effects of two changes such as these should be identical, the effects depicted in the JCT's distributional tables were strikingly different, and, as a result, the tax increases necessary to "neutralize" the distribution effects of the immediate deduction form of tax cut were one-fifth the size of the tax increases necessary to neutralize the capital gains rate cut.

Likewise, the potential regressivity of proposals for increased tobacco taxes concerned members of Congress in both 1990, when these taxes were most recently increased, and again in 1994, when legislators considered a tobacco tax increase as a means to finance part of President Clinton's health care reform proposals. In distributing the burden of these tax proposals to income classes, JCT distributes the static revenue lossthe increased taxes that would be paid if no one stopped or reduced smoking in response to the change in taxes-even though this reduction in smoking is the behavioral response that proponents of this particular tax increase are attempting to induce. Politicians not intimately familiar with JCT methodology would naturally tend to assume after looking at JCT's distributional tables that the burden of such a tobacco tax increase is far more regressive than JCT actually estimates the financial burden will be. Again, to offset such a tax increase to achieve distributional neutrality in JCT's tables, a far larger tax reduction would have to be enacted for the income classes burdened by the tobacco tax increase. And, once again, the distributional consequences of such changes would look quite different retrospectively; a change shown as distributionally neutral when viewed prospectively would be reflected as an overall tax reduction when subsequent distributions of existing taxes are taken into account.

For a related example, consider Senator Daniel Patrick Moynihan's 1994 proposal for a massive tax increase on certain forms of ammunition. Here, Senator Moynihan clearly intended to increase the price of such ammunition so that virtually no one would purchase it. A reasonable revenue estimate of the tax increase would be approximately zero. Unless

57: See News Analysis: Small Business Incentives: An Eight-Fold Path to Who Knows Where? 49 Tax Notes 133 (1990), available in LEXIS, Fedtax Library, INT File. For a demonstration that immediate deduction of the cost of an asset is equivalent in present value to exempting the gain, see Michael J. Graetz, Federal Income Taxation: Principles and Policies 386-389 (2d ed. 1988). There were other important differences in the capital gains and immediate deduction proposals that affected the magnitude of the revenue losses of the two proposals. The capital gains proposal applied to all existing assets, for example, while the immediate deduction would have applied only to newly-purchased assets. But the basic point of the text-the multiplier effect of distributing the burden of capital gains - holds true with respect to a capital gains proposal applicable only to newlypurchased assets. The static revenue loss from an immediate deduction did not take into account stock purchases stimulated by the new tax incentive, and it therefore produced far smaller effects in the distributional tables. 
JCT abandons its standard practice, however, its distributional table showing the effect of the increased ammunition taxes due to the rate increase-which ignores behavioral changes-would show a very large tax increase for a handful of people. This seems to be an example of the kind of case in which JCT, as it pamphlet suggests, would probably "exercise its judgment and adjust the burden from the static revenue estiinate. ${ }^{n 8}$ Whether the proposed tobacco tax increase would fall into that category or not is a mystery. Moreover, policymakers are not likely to know when such adjustments are made or what their size is.

In my view, the JCT staff decision to attempt to estimate changes in "burdens" rather than changes in taxes is a disservice to the political process. First, there will often be no reason to believe that the static revenue estimate is a good measure of "burden." For example, some people would quit smoking in response to a twenty cent increase in the cigarette tax, just as they would in response to a one-dollar increase. For these people, even under the JCT reasoning, a twenty-cent tax increase is the correct measure of their burden, not a one-dollar tax increase. This point holds true for all people who would quit smoking in response to a tax increase smaller than the one proposed. Second, if one believes that the appropriate distributional question relates to the changes in after-tax incomes that result from the change in the tax law, the static revenue loss generally is totally disconnected from that measure..$^{59}$

Third, the JCT tables are constructed in a manner that always will produce different results looking forward and looking backward, even if all of the important variables turn out to be exactly as the JCT estimates they will be. If one expects policymakers to look both forward at distributional effects of proposed changes and backward at the distribution of taxes after the change, one will find that the JCT staff predictions never match experience. Couple this problem with the fact that the first two columns of the JCT table depict distributions of existing taxes and columns 3 and 4 show distributions of changes in "burdens," and JCT's decision to distribute burdens seems inevitably to add confusion to the policy process.

Fourth, even if one believes that the static revenue loss is a better measure of "welfare loss" or "economic burden" than the actual tax increases that will occur, JCT's decision to distribute the static revenue loss remains troubling. The effort to measure welfare loss does not seem to answer the question that political decisionmakers are asking. Inevitably, notwithstanding the JCT's admirable recent publication of its methodology and its new willingness to discuss this issue publicly, JCT tax distribution tables will be understood by political decisionmakers and the public at large as estimates of the distribution of the change in taxes that the

58. JCT, Measuring Tax Burdens 1993, supra note 23, at 29.

59. See the discussion of Lorenz curves and Gini coefficients, supra text accompanying notes $33-35$. 
changes in law are expected to produce. Of course, this objection might be dismissed as tautological. If the question the policymaker is askingor thinks she is asking-relates to the distribution of the changes in the taxes that actually will be paid, any answer that departs from this measure obviously is inappropriate and has the potential for mischief in the political process. Different people may reach opposite judgments about the question being asked, but having tried on a number of occasions in 1990 to have policymakers of both political parties comprehend the JCT's methodology, I am confident about the potential for misunderstandings.

Finally, further confusion results from the fact that the Treasury and Congressional staffs have reached differing judgments on this matter. When tax changes are not expected to induce substantial changes in behavior, the estimated static revenue change will not differ significantly from the revenue estimate itself, and OTA and JCT tables will look very similar. For example, tables reflecting increased personal exemptions or limitations on deductions for state income taxes will look very similar whether produced by OTA or JCT. On the other hand, there will be important differences in distributional estimates shown by OTA in distributing actual taxes and the JCT in distributing static revenue losses in every instance where the expected behavioral responses to a tax change are large. Tables grouping large numbers of proposed changes will often include proposals of both sorts.

Multiple presentations of such information may have advantages and disadvantages. They will demonstrate a wide range of answers for policymakers, and when the political masters of the Treasury and Congress are members of the same party, this may be useful. But when the parties controlling the Executive and the majority in Congress are different, as is so often the case, each staff will be accused of manipulating data for political purposes or caving in to please their political masters. Surely this undermines the reliability of the tax policymaking process. Multiple presentations by the same staff would avoid this problem and probably should be encouraged.

Although OTA's practice of distributing estimated changes in taxes generally produces a better estimate of the effects of tax changes on aftertax income and thus seems preferable to JCT's practice of distributing static revenue changes (as a proxy for welfare or burden changes), there are occasions when the distribution of estimated revenue changes itself might be misleading. For example, OTA estimated that President Bush's proposed exclusions from income of a portion of capital gains would increase federal revenues in both the short and long term by inducing suffcient additional realizations of capital gains so that taxes assessed on these additional realizations were predicted to more than offset the taxes lost due to the exclusion of a portion of gains. OTA distribution tables therefore showed a tax increase for the upper income classes in circumstances where these people clearly would benefit, not suffer, from a capital gains tax cut. Obviously, the idea that these income groups "deserve" 
some additional tax reduction to offset this increase in taxes is absurd. The existence of such anomalies offers further evidence of the dangers of decisionmakers simply relying on the numerical answers provided by distributional tables to determine the effects of their policies rather than directly addressing the question of what kinds of offsetting changes, if any, are necessary to achieve results that can be agreed upon a fair.

Thus, both staffs' methodologies may have significant shortcomings when assessing certain types of policy changes. Yet relying on the staffs to make ad hoc adjustments to their standard methodologies when "appropriate" to achieve "reasonable" results would give extraordinary discretionary power to the staff and would create significant potential for mischief. In contrast, there is little disagreement about the general distributional consequences of the kinds of tax changes that $I$ have discussed here. It would be quite easy for JCT and Treasury staffs to describe in narrative form the general effects on people at different income levels of tax changes such as these. However, the process of quantifying the effects of such changes inevitably introduces distortions.

2. The Measurement of Income. - Although all three of the relevant tax staffs use an annual measure of income rather than a lifetime measure, ${ }^{60}$ there nevertheless is considerable divergence in how the staffs measure annual income. JCT uses a concept of "expanded income," which adds to adjusted gross income for federal income tax purposes estimates of certain cash receipts not included in adjusted gross income. JCT includes tax-exempt interest, workers' compensation payinents, certain federal entitlement benefits under Social Security and Medicare, and certain excluded employer-paid fringe benefits such as health and life insurance. However, JCT does not permit certain deductions disallowed under the minimum tax (for example, state and local taxes) and makes an adjustment relating to corporate taxes. Under this measure of "expanded income," JCT includes capital gains only when they are realized through the sale of assets and includes retirement income when it is actually received rather than when contributions are made by individuals or employers to retirement plans or when income is earned by such plans on behalf of their beneficiaries.

OTA, on the other hand, classifies taxpayers by a very different measure of income. OTA attempts to measure "economic income" by including accruals of capital gains and losses, without regard to whether they are realized for tax purposes. OTA estimates include imputed income as it is earned in pension funds and as it accrues in the form of interest buildup on life insurance. OTA also expands the definition of income to include a much greater range of nontaxable government transfer payments, such as AFDG, and includes imputed rent on owner-occupied housing.

60. See infra text accompanying notes 95-97. 
OTA attempts to adjust its estimates of accrued capital gains for inflation, an adjustment that is not made by either of the other two staffs; apparently, none of the staffs adjusts interest income or expenses for inflation. This means that whenever inflation occurs, interest income is generally overstated, as are interest deductions, in comparison to inflation-adjusted real incomes. These misstatements distort policymakers' ability to compare the relationship of taxes to real income both among different taxpayers (depending, for example, upon their borrowing and lending practices) and for the same taxpayers across years (since taxpayers with identical real incomes typically have different nominal incomes in different years).

No doubt most economists would agree that the Treasury's broader measure of economic income is theoretically more appropriate, but the data available to the JCT are more reliable. Indeed, the JCT describes its income concept as "a considered compromise between theory, ease of implementation, and understandability." 61 As is well recognized within the tax professional community, there are many alternative measures of income that might be used by these staffs. Indeed, CBO uses a third ineasure which is based upon cash receipts and is closely linked to the federal income tax code's definition of income. CBO ignores noncash income, accrued, but unrealized, changes in family wealth, and imputed income. ${ }^{62}$ Thus, CBO's measure of income is closer to JCT's definition than it is to OTA's. Figure 4 shows the different estimates of effective tax rates of pre-1993 tax law under the three staffs' different income and classification measures.

61. JCT, Measuring Tax Burdens 1993, supra note 23, at 16.

62. See Kasten, supra note 24. 


\section{FIGURE 4}

Effective Federal Rates

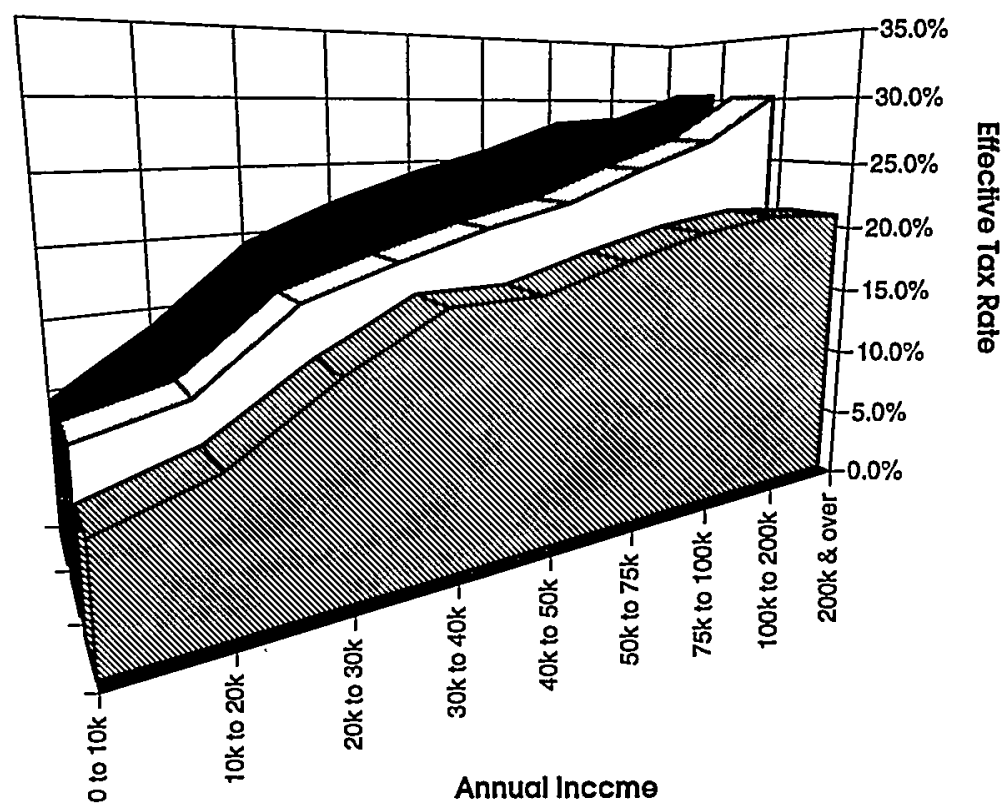

\begin{tabular}{l}
\hline STreasury \\
口JCT \\
aCBO \\
\hline
\end{tabular}

Sources: OTA, Feb. 1993. JCT, 1993, Table 2. CBO Memorandum, Feb. 11, 1993.

1. Numbers are given as a percentage cf pre-tax income.

2. OTA numbers are of 1994 income levels, JCT and CBO numbers are at 1993 income levels.

Obviously, the tradeoff between greater theoretical purity and more reliable data is a judgment that different staffs can be expected to make differently, and, indeed, that even the same staff might make differently at different times. JCT emphasizes the importance of understandability in choosing an income measure, although there is considerable irony in this choice, given its decision to measure changes in economic burden rather than changes in taxes. People probably will have different judginents about the importance of public understandability as a criterion for constructing distributional tables. Consider, for example, OTA's decision to include in income imputed rent on owner-occupied housing. Tax policy experts recognize such imputed rent to be income in theory, ${ }^{63}$ and people readily understand that taxpayers who own their own homes generally are wealthier than those who do not. If distribution tables were constructed with respect to wealth, an adjustment for owner-occupied housing would be important and straightforward, and several of OTA's

63. See, e.g., Graetz, supra note 57, at 153-54. 
adjustments can be understood as ways to take differences in wealth into account through the income measure. On the other hand, most people do not view imputed rent as income. Consider the following comments of ABC News' David Brinkley:

Finally, a few words about federal taxes and what some of the great minds in the U.S. Treasury are thinking about.

The Treasury likes to calculate the American people's ability to pay taxes based not on how much money we have, but on how much we inight have or could have had. For example, a family that owns a house and lives in it, the Treasury figures that if the family didn't own the house and rented it from somebody else, the rent would be $\$ 500$ a month. So it would add that amount, $\$ 6,000$ a year, to the family's so-called imputed income. Imputed income is income you might have had, but don't. They don't tax you on that amount.

The IRS does not play this silly game. Instead the Treasury calculates , how much they could take away from us if they decided to. If that were the system, consider the possibility. How about being taxed on Ed McMahon's $\$ 10$ million magazine lottery? You didn't win it, you say? But you could have. The Treasury must have something better to do. If not, there is a good place for Clinton to cut some spending. ${ }^{64}$

Politicians (and the public generally) would no doubt have reactions similar to those expressed by Brinkley. The important question here is the tradeoff between the benefits of greater theoretical precision and the costs of public bewilderment or distrust. Obviously, the different tax staffs have reached different judgments as to which aim should prevail.

3. The Unit of Analysis: Families, Couples, Individuals, or Households. - In showing the distribution of existing taxes and proposals for change, the determination whether and how to aggregate members of a family or household is important. Treating each individual separately would clearly be a poor choice. It would, for example, generally treat non-working spouses and young children, who have no independent income, as having zero or low income, without regard to the monies earned by a working spouse on behalf of the family. Nevertheless, the individual is routinely the unit of analysis in widely used per capita income statistics. In principle, since a family's or household's aggregate income is typically shared for living expenses, the family or household is the appropriate unit for use in distributional tables. For many people, the unit "family" and the unit "household" are interchangeable and would generally serve to aggregate income of parents and dependent children, while ignoring variations in patterns of earning or sharing income.

On the other hand, when a nuclear family has split apart, aggregation of all family mcome does not seem appropriate. Some adjustment is

64. David Brinkley, ABC News' This Week with David Brinkley, Feb. 28, 1993, available in LEXIS, News Library, Reutrn File. 
necessary to account for alimony or child support payments. In practice, the allocation of these payments in distributional tables will tend to turn on their statutory tax treatment, which, for all practical purposes, is essentially elective. Even when the family stays together, questions remain, such as when a child should be treated as having moved outside the family unit and thus regarded as a separate unit for distributional analysis. Similar questions occur when there are dependents in the household who are not children-for example, grandparents residing in the parents' home.

It is surprising that despite the staffs' general theoretical consensus that the family or household is the appropriate unit for analysis, each staff follows a different approach in classifying taxpayers. The JCT staff, in light of the difficulty of constructing family or household income from data available on tax returns, chooses to stay close to the information available from tax returns and classifies taxpayers based on tax filing status. JCT thus generally does not include minor children along with their parents; instead JCT generally ignores dependents in constructing distributional tables..$^{65}$ Because JCT takes no account of dependents who file separate returns, its methodology eliminates nearly fifteen percent of returns filed. JCT expects to aggregate family income in the future when the quality of tax data improves through better Social Security number matching. 66

In contrast, OTA and $\mathrm{CBO}$ apparently regard the theoretical advantages of using family or household units as outweighing the disadvantages of having to impute incomes among different tax returns. Thus, despite the shortcomings of the data available to them, both OTA and CBO use statistical analyses to estimate total family income and use the family as their base unit for analysis. There are also a variety of approaches for determining the division of income within the family. ${ }^{67}$ For example,

65. See JCT, Measuring Tax Burdens 1993, supra note 23, at 13 n.16, 97.

66. See id.

67. This issue is demonstrated in the following example from Atkinson:

The choice of weights may make a significant difference. Some of the effects may be seen from the simple example of a hypothetical, male-dominated, society where there are 20 men each with wealth of $20,000,80$ men with 7500 , and 100 women with no wealth. All the 20 rich men are married, as are 40 of the 80 men with 7500 , leaving 40 single men and 40 single women. On an individual basis (commonly employed im wealth statistics, since they are often based on records of estates at death), the top 10 percent ( 20 out of 200 ) own 40 percent of the wealth ( 400,000 out of 1 million). Suppose now that we consider the total wealth of the family $(Y)$, and first treat all families, or single individuals, as one unit .... There are 140 such families, so that 40 percent of wealth is owned by 14.3 percent (20 out of 140) of families. On the other hand, suppose that we treat a married couple as two units, each with the benefit of $Y$ wealth. This means, of course, that the total 'equivalent' wealth is now greater than 1 million (it rises in fact to 1.7 million), which may upset the accountants but is logically quite correct. The 20 rich couples account for 20 per cent of the effective population, and benefit from 47.1 percent $(800,000$ out of 1.7 million) of the total equivalent wealth. However, 
OTA uses the family as the unit of analysis and attempts to aggregate the income of parents and their children. CBO uses a methodology common in social scientists' analysis of poverty and applies an income equivalent scale to "standardize" families' and households' incomes based on their differing sizes.

The need to allocate income of entities to individuals or families also causes some difficulties. For example, how does one allocate to the tax returns of families, individuals, or married couples the income (and attendant taxes) of a trust that is accumulating income, the subsequent distribution of which is at the discretion of a trustee? Likewise, after a family member's death, income can be taxed to an estate over a period of years awaiting final determination of how the income is to be distributed; this also causes difficulties in allocating income to the appropriate income class. ${ }^{68}$

Once the staff determines the family unit and measure of income to be used in constructing distributional tables, people are allocated to various income classes. Table I, for example, groups people into nine income categories. Distinctions among families in the same income class are not captured in the distributional table even though in many instances intragroup differences may be more significant than intergroup differences. For example, if Congress were sufficiently concerned about the regressive impact of a tobacco tax increase to enact an offsetting tax reduction so that the distributional table would show no change for people in a particular income class, say in the $\$ 20,000$ to $\$ 30,000$ class, there is no reason to assume that the families (or couples) who would be subjected to the tax increase are the same as the families (or couples) who would benefit from the tax reduction. Indeed, this common use-I argue misuse-of a distribution table views a tax increase on smokers as demanding an offsetting tax reduction for nonsmokers. All a distributional table can show is the overall impact on all the families (or individuals or couples) within the same income classification. This rather obvious point often seems to be lost on policymakers. Moreover, the organization of the tables by specified amounts of income-the choice of breakpoints-is itself arbitrary. These nominal income distributions contain very different numbers of people; for example, in 1993 the top classification (over $\$ 200,000$ ) contained just over one percent of the taxpaying population, while the bottom classification (under $\$ 10,000$ ) contained nearly fifteen percent. ${ }^{69}$ Organizing the tables by population-say, by

if we treat a couple as two units, but only allocate each a benefit of $Y / 2 .$. then the top 20 percent has 40 percent of total wealth (which in this case remains at 1 million). The reader should consider other possible variations, including the cases where some of the wealthy are not married and where women possess wealth.

A.B. Atkinson, The Economics of Inequality 52-53 (2d ed. 1983) (sexism in the original). 68. Related issues arise in allocating corporate income and, to a lesser extent, partnership income.

69. JCT, Measuring Tax Burdens 1993, supra note 23, at 106. 
deciles-would simply create the opposite problem; the numbers of units in each category would be the same but the lowest decile would represent only one percent of the JCT's income measure while the top decile would represent inore than thirty-five percent of the income.70

4. The Relevant Time Horizon. - The different staffs disagree about the appropriate time horizon over which changes in the tax law should be evaluated in order to estimate their distributional impact. OTA-like the JCT prior to May 1, 1992-assesses the distributional consequences of a set of legislative changes and attributes them entirely to the year in which all of the changes are fully phased in. JCT now rejects this treatment on the ground that it is distorting, for example, with respect to all temporary provisions, particularly those that expire within the budget horizon, which would not be reflected at all in the OTA table. Instead, JCT now generally uses a rough five-year average impact of the tax changes on the ground that the five-year budget period-prescribed by law as the relevant period for revenue estimating-is the appropriate time horizon to legislators. ${ }^{71}$

The JCT contends that the "correct approach" would be to calculate the present value of the burden of a tax change in each future year into the indefinite future, which involves applying an appropriate interest rate to discount this stream of annual burdens. ${ }^{72}$ However, the frequency, indeed the likelihood, of changes in both the tax law and interest rates in the future makes it questionable whether this approach is indeed "correct."

As with the differing choices about units for classifying people, there are arguments supporting each of the staffs' judgments. In some cases, important differences in distributional tables will result from these different time horizons since the maguitude of the change may well depend on the time period in which it is considered. Moreover, each staff tends to ignore wealth effects that may be important because of changes in the values of existing assets that occur due to transitions from existing to new law. 73

5. Tax Incidence Assumptions. - Probably the greatest gulf between what experts know about taxes and what the public and most politicians believe is that the economic burden or "incidence" of a tax is often quite different than its statutory burden. In particular, taxes imposed on and paid by a business entity inust ultimately be borne by people: the business's owners, its einployees, its customers, or some combination of these people and perhaps others. The majority of the public seems to fail to appreciate tax shifting, even when economists are unified in their view

70. See id. at 105.

71. See id. at 31-36.

72. Id.

73. For a discussion of the effects of tax law changes on asset values, see generally, Michael J. Graetz, Legal Transitions: The Case of Retroactivity in Income Tax Revision, 126 U. Pa. L. Rev. 47 (1977). 
about which group of taxpayers ultimately will bear the burden of the tax. For example, there is essentially no dispute in the economic literature that virtually all of a payroll tax will, in the long run, be borne by employees in the form of lower wages. Despite the economic consensus, however, workers clearly seem to prefer taxes paid by employers to taxes paid by themselves, and it would be wrong to fault them as completely naive. In the short run, the incidence may well be different because employers may be prohibited by law, contract, habit, or economic conditions from immediately shifting the burden of the tax to employees by lowering wages. This short-term advantage, however, may serve to make employees myopic about long-term consequences of payroll taxes and thereby may affect substantially the politics of these taxes.

In the case of other taxes, economists frequently disagree about the shifting of the tax burden. For example, who bears the true burden of the corporate income tax has long been controversial among economists. Moreover, the economic incidence of a tax may depend far more on its details than the economic literature usually suggests. For example, the appropriate incidence assumptions about corporate income taxes may depend on the details of corporate tax law, in particular on the rules for the recovery of capital expenditures. Liberal capital expenditure allowances may have the effect of shifting the corporate tax burden from owners of capital to labor. ${ }^{74}$ In their examination of the 1984 corporate income tax, Fullerton and Rogers suggested that the corporate income tax should be analyzed, not in the traditional manner of corporate income taxes, but rather in a manner similar to variable excise taxes on different types of consumption. This suggestion was motivated by the wide variations in the burdens borne by different corporations, depending on their capital structure, as well as their industry. ${ }^{75^{\prime}}$ Today's corporate income tax is considerably more neutral across industries than it was a decade ago, but there may still be enough variations to induce excisetype tax effects.

Until recently, JCT did not distribute corporate income tax changes at all on the ground that the incidence of the tax was too uncertain. JCT's refusal to distribute corporate tax changes had enormous practical consequences for policymakers relying on distributional tables as a basis for their political decisions. Not distributing corporate income taxes created political incentives for policymakers to locate tax-reducing provisions at the corporate level (where they would not reduce progressivity in the distributional tables) and tax increases at the shareholder level (where they would increase progressivity in the distributional tables). In the 1990 budget negotiations, for example, it was not possible to offset regressive distributional burdens of selected excise taxes on the middle class through corporate tax changes, and President Bush would not agree

74. See Fullerton \& Rogers, supra note 24 , at 76-91.

75. See id. 
to significant individual income tax rate increases. In addition, under this distributional methodology, economically similar policies would be treated very differently in the distributional tables; for example, integration of the corporate incoine tax in the form of a dividend exclusion or shareholder credit for individuals would show up as a substantial tax reduction for high income individuals, while corporate tax integration through a deduction for corporate dividends would be ignored in the tables.

Since 1992, JCT has allocated both corporate income and related corporate taxes to owners of capital generally. OTA uses a similar incidence assumption. In contrast, the CBO has used three corporate tax incidence variations in recent years, sometimes treating the tax as borne by owners of capital, sometimes treating the tax as borne by labor (which the CBO says is more appropriate in an open econoiny with global capital markets), ${ }^{76}$ and sometimes allocating the tax half to labor and half to capital. ${ }^{77}$ As Figure 5 shows, differing corporate tax incidence assumptions are significant in assessing the distribution of tax burdens and tax changes.

76. See Congressional Budget Office, The Changing Distribution of Federal Taxes: 1975-1990, 22-23 (1987); cf. Jane G. Gravelle, Corporate Tax Incidents in an Open Economy, 1993 Vol. of the Proc. of the Nat'l Tax Ass'n 173 (1994) (contending corporate taxes are borne by capital even in an open economy with global capital markets).

77. See Kasten, supra note 24, at 8 (stating that recent CBO studies "assumed that half of the corporate income tax was allocated to all income from capital and half to labor income"). 
FIGURE 5

Effective Tax Rates with Varying Corporate Tax Allocation

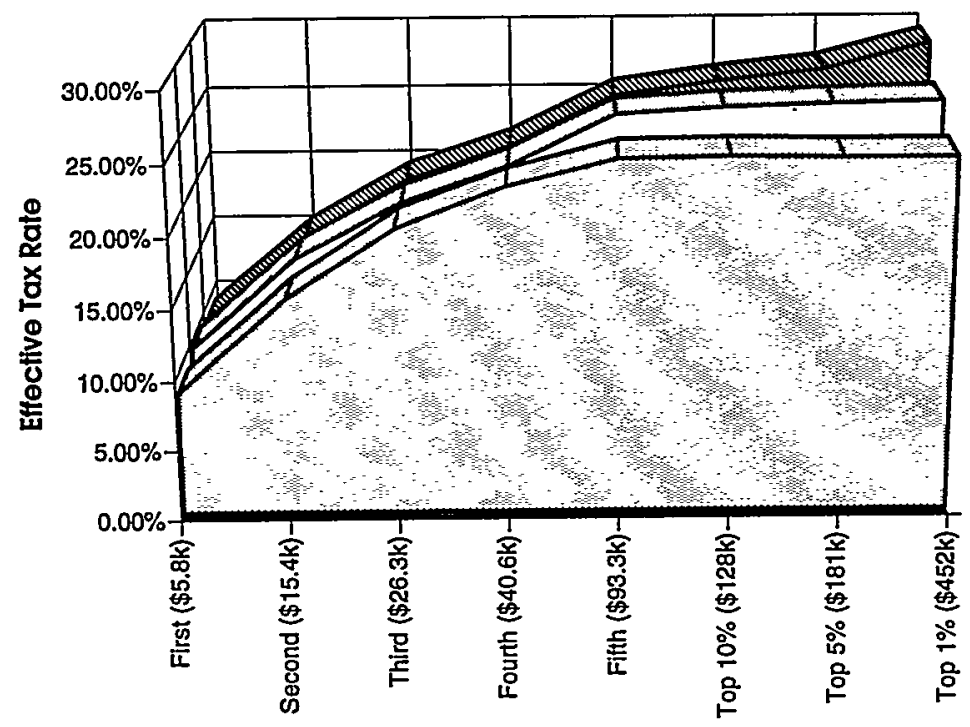

Annual Income Quintile

\begin{tabular}{|l|}
\hline$\square$ Labor \\
$\square 1 / 2 L, 1 / 2 C$ \\
$\mathbb{\text { C Capital }}$ \\
\hline
\end{tabular}

Sources: CBO 1975-90, Tables 6, 7 \& 8. Ways and Means, 1991, Table 14.

1. All numbers are of 1988 income levels.

2. The numbers in parentheses are the overage incomes for each income class.

Concerns and ambiguities about the economic incidence of taxes and tax changes create enormous problems for staffs attempting to construct distributional tables. Obviously, making firm assumptions when tax incidence is uncertain or controversial can have a major influence on policy. For example, the decision to allocate the corporate income tax burden completely to owners of capital, rather than to divide it evenly between owners of capital and labor or consumers, concentrates that tax in the higher income brackets. If those analysts who contend that consumers or workers bear at least part of the burden of the corporate income tax are correct, the current distributional tables make the existing tax system appear more progressive than it actually is. Currently, in order to make a distributionally neutral change to offset a reduction of corporate income taxes, higher taxes must be imposed on upper income individuals. To the extent that the corporate tax is borne in part by consumers or workers, reductions in corporate taxes would, in fact, be spread more generally across income classes. Finally, if corporate income taxes are particularly inefficient and inhibitive of economic growth, as many economists believe, tradeoffs between efficiency and equity look quite dif- 
ferent depending on how the incidence of the corporate tax is assigned in distribution tables.

The problem of allocating corporate imcome and corporate taxes by income class is further complicated by the desire to treat equivalent policies consistently in distributional tables in order to maintain a semblance of policy coherence and to limit gamesmanship. JCT's pre-1992 practice of distributing changes in individual taxation of corporate source income but not distributing changes in taxes at the corporate level, as suggested earlier, created a bias im favor of a dividend deduction method of integration over shareholder-level inethods, such as dividend exclusions or shareholder credits. This choice was made even though it would have substantial effects on other issues, such as the impact of integration on tax exempt entities and foreign shareholders. ${ }^{78}$ JCT's current methodology eliminates this kind of problem by allocating the corporate tax entirely to owners of capital, thereby treating a dividend deduction method of integration as generally equivalent to a shareholder credit or dividend exclusion. However, this parity would not exist if, for example, part of the corporate tax were allocated to consumers or to labor, given that the distributional tables for shareholder-level integration would be constructed using the standard assumption that the individual income tax is not shifted. ${ }^{79}$

A proper desire for consistency in demonstrating distributional burdens of policy equivalents creates additional conundrums for the staffs. To take an important example, JCT now distributes a value-added tax, or any other broad-based consumption tax, to wage earners and existing owners of capital rather than in the more traditional manner of distributing the burden entirely to consumers. This method allows the distribution of consumption taxes when the income is earned and parallels the treatinent of income or wage taxes. ${ }^{80}$ As Figure 6, which is reproduced from the 1993 JCT distribution pamphlet, shows, this allocation of consumption taxes to earners rather than consumers produces a burden of consumption taxes that differs from the typical allocation to consumersparticularly those at the higher end of the income distribution. Again, this decision may have important policy implications: The new JCT method of allocating consumption taxes means that replacing income taxes with consumption taxes would require a much smaller offsetting tax increase on high income taxpayers in order to produce neutrality in a JGT distribution table.

78. See U.S. Treasury Dep't, Corporate Tax Integration: Taxing Business Income Once 36 (1992).

79. For a suggestion that individual level taxes on businèsses conducted in the partnership or proprietorship form might be partially shifted, see Boris I. Bittker, Effective Tax Rates: Fact or Fancy? 122 U. Pa. L. Rev. 780, 799 (1974).

80. See JCT, Measuring Tax Burdens 1993, supra note 23, at 51-60. 


\section{Figure 6}

Burden of a 5\% Broad-based Consumption tax as a Percentage of Pre-TAX INCOME

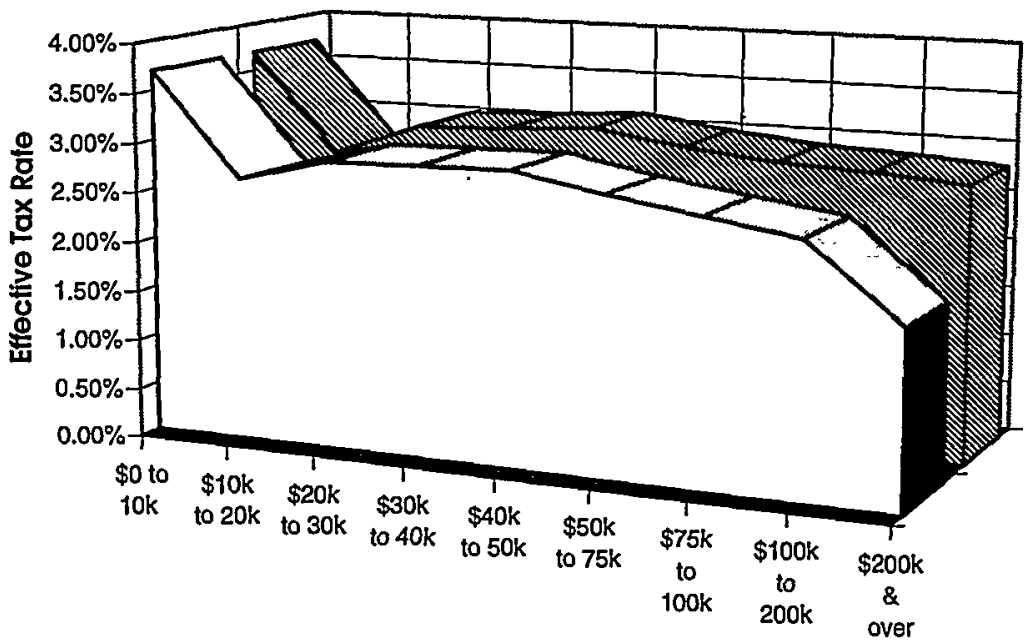

Annual Income Class



Source: JCT. 1993, Table 3.

1. (D,C) is the traditiond method of distributing a consumption tax-to consumption.

2. (p.Y) is the method adopled by the JCT in 1993-distribution to wages and old capital.

Consumption taxes may take a variety of forms. For example, states in this country routinely impose retail sales taxes; the European Community uses credit-method value-added taxes; Canada uses a subtractionmethod value-added tax. A subtraction method value-added tax (or business transfer tax) has similar incidence and should be distributed in a manner similar to a credit-method value-added tax. Some advocates of such a tax, however, prefer the labels "cash flow corporate income tax," "uniform business tax," or some other term to the label "value-added tax." Needless to say, one cannot change one's judgment about tax burdens as labels change, a point that emphasizes the need to examine the details of a tax in order to know how to distribute it. ${ }^{81}$

81. This also underlines the point made above that capital recovery allowances in the direction of expensing of capital purchases move the corporate income tax burden away from capital and on to labor. See supra text accompanying note 74. This may raise doubts about the judgment of both OTA and JCT that corporate taxes sbould be allocated entirely to capital in distribution tables. On the other hand, an allocation of the corporate tax entirely to capital might be defended as the most conservative course if JCT and OTA distributional estimates were intended to protect against changes that might inadvertently make the distribution of after-tax income less equal. 
The problem of assessing tax incidence is pervasive. To take one additional example, economists tend to agree that an excise tax imposed on final consumers of a particular product is a tax on consumption. Each of the three staffs generally distribute selected excise taxes consistent with that premise, although their methodologies vary. In the short term, however, producers and workers in the industries affected may bear the burden of the tax. This phenomenon was widely believed to have occurred in connection with the ten percent excise tax on luxury boats adopted in the 1990 Budget Act. ${ }^{82}$ Advocates for the boating industry, some independent economists, and virtually all politicians came to believe that instead of burdening the very wealthy purchasers of luxury yachts, as had been intended, the excise tax burden in the period immediately following enactment was borne predominately by laborers engaged in the construction of such boats. ${ }^{83}$ Putting aside the truth of this judgment, ${ }^{84}$ the standard decision to ignore short-term distributional effects of taxes was proved wrong in this case. Once Congress was given information regarding the perceived short-term effects of the tax, Congress repealed it.

As this example illustrates, political decisionmakers would probably like to know both short-term and long-term distributional consequences of legislative decisions, particularly when a serious impact on labor in concentrated areas or industries might reasonably be predicted. Short and long term differences are much more easily captured through a narrative report of the distributional consequences of proposed legislation than through distributional tables.

If the affected workers are abroad, political consequences may be the opposite. Congress, for example, might be little concerned-or even pleased-if the excise tax on so-called gas-guzzling automobiles was borne by the workers who produce these automobiles, not, as the distributional tables suggest, by purchasers of these automobiles, since much of the production of these cars occurs abroad. Distributional tables simply do not alert decisionmakers to the potential consequences of their actions in circumstances like these. Nor do they alert decisionmakers to regional variations in the tax burden, as for example, occurred with the luxury excise tax on boats. However, regional differences generally are

82. See OBRA 90, supra note 5 , at $\$ 11221$.

83. For reactions to the tax, see, e.g., House Passes Revenue Act of 1992, 356 to 355, Tax Notes Today, July 16, 1992, available in LEXIS, Fedtax Library, Taxtxt File (comments of Rep. Clay Sbaw); Senate Passes Unemployment Compensation Bill, by 66-33, Tax Notes Today, Mar. 16, 1993, available in LEXIS, Fedtax Library, Taxtxt File (comments of Sen. George Mitcbell).

84. The discussion in the text offers a very shorthand description to make the point that short-term and long-term effects may differ in significant ways that are not taken into account in the distributional tables. How the change itself is accounted for would depend importantly, for example, on whether "burden" or "taxes" are distributed and on a number of other factors. See Dennis Zimmerman, Congressional Research Service, The Effect of the Luxury Excise Tax on the Sale of Luxury Boats (1992) (noting factors that affect demand for luxury boats). 
treated as a horizontal, not as a vertical, equity issue, and are not reflected at all in distributional tables.

Excise taxes enacted for the specific purpose of correcting externalities or reducing consumption of specific goods are taken up below.

\section{Controversial Areas of Staff Agreement}

I now turn to some important areas where the staffs agree. Agreement does not, however, signal that an issue is settled or non-controversial. Despite staff agreement, many important issues remain.

1. Tax Capitalization and Implicit Taxes. - As the preceding discussion of tax incidence suggests, a fundamental issue in constructing distribution tables is how to treat market reactions to various taxes and changes. Obviously, by distributing taxes in accordance with their economic rather than statutory incidence, each of the staffs takes certain kinds of market responses into account in constructing distribution tables. No reasonable analyst advocates distributing the burden of tax legislation by its legal rather than economic incidence, notwithstanding the uncertainties involved in the latter exercise. However, the determination of when to stop attempting to take market reactions into account is not easy. This problem is well illustrated by the distributional treatment of the 1986 Tax Reform Act's limitations on tax shelter investments.

In 1986, Congress enacted a major tax reform that was said to be distributionally neutral and revenue neutral. Apparently, this was taken to mean that the legislation should be revenue-neutral in each income class. ${ }^{85}$ However, durmg the 1970 s and early 1980s, many high income taxpayers had invested in a wide variety of so-called tax shelters. Investments in real estate, exploration and development of oil, gas and other natural resources, motion picture production, and certain farming activities were all eligible for tax benefits and were favored tax shelter investments. Eliminating the widespread availability of such tax shelters was an important substantive goal of the 1986 Act. ${ }^{86}$ In making these kinds of tax-advantaged investments under the pre-1986 law, taxpayers reduced their income taxes, but typically at the cost of a lower pre-tax return from the tax-shelter investment than they would have received from an investment of similar risk that did not enjoy tax advantages. No good measurement of the adjustments to pre-tax returns in the tax-favored areas, however, was available for use by the relevant tax staffs.

In contrast, the magnitude of these effects in the case of tax-exempt state and local bonds can easily be determined from the difference in return on tax-exempt and taxable bonds of similar maturity and risk. His-

85. See Steuerle, supra note 2, at 106-08. If "burdens" rather than taxes were distributed, the legislation would have had to be "burden" neutral in each income class.

86. See Mark N. Uhlfelder \& Eric S. Kracov, Summary of Major Provisions Accepted by Tax Bill Conferees, reprinted in Tax Analysts, Tax Notes Today, Aug. 22, 1986, available in LEXIS, Taxana Library, TNT File. 
torically, returns on state and local bonds have ranged between about seventy and ninety percent of returns on comparable taxable bonds. There is a large literature discussing the reductions in pre-tax rates of return for holders of tax-exempt bonds-reductions that have come to be called "implicit taxes"-and evaluating the efficiency and equity implications of the trade-off between lower interest rates and tax savings. ${ }^{87}$ Even when data are available, however, distributional tables typically reflect these kinds of reductions in pre-tax rate of return only in measuring taxpayers' incomes. The tables do not treat implicit taxes as a tax incidence issue.

The best treatment of implicit taxes is far from clear, but the staffs' uniform decision to ignore the widespread tax shelter phenomenon in its distributional tables in 1986 had important effects. In determining the 1986 tax rates necessary to achieve distributional neutrality, Congressional decisionmakers relied on distributional tables to determine the tax rates necessary only to compensate for actual taxes paid at each income level, ignoring the implicit taxes-reductions in the pre-tax returns-on tax-favored assets. In combination with the direct restrictions on tax shelters in the 1986 Act, this rate schedule prompted a shift away from tax shelter investments into taxable investments. This shift necessarily produced higher pre-tax mcome for these upper bracket taxpayers, which, given substantially lowered rates on upper income individuals under the new rate schedule, would naturally result in a foreseeable reduction in progressivity from purportedly "distributionally neutral" tax legislation. In 1986, this effect on progressivity was exacerbated by the fact that much of the tax increase for upper-income taxpayers was in the form of retroactive tax increases on pre-1986 tax shelter investments, tax increases that had only a temporary impact in increasing taxes of upper-income people, even though the provisions themselves, as well as the accompanying rate reductions, were permanent changes in the law.

This standard practice of ignoring changes in pre-tax returns on taxfavored assets also dramatically distorts distributional tables that are produced annually by JCT to show the distributional effects of particular tax expenditures. Using quite different methodologies, David Bradford and I (at an interval of about a decade) attempted to "correct" the official estimates showing the distribution of the benefits resulting from exclusion of interest on tax-exempt bonds. I proposed to correct this distribution by reflecting the interest cost savings of state and local governments, reflected in the investor's lower pre-tax return, on the assumption that the additional interest costs that would result from repealing the tax exemption would have to be made up through increased taxes by the state

87. See, e.g., Boris I. Bittker, Equity, Efficiency, and Income Tax Theory: Do Misallocations Drive Out Inequities?, in The Economics of Taxation 19 (Henry J. Aaron \& Michael J. Boskin eds., 1980). 
and local governments. ${ }^{88}$ David Bradford took quite a different approach and attempted to measure the implicit tax impact more directly by constructing effective tax rates, taking into account the reductions in pre-tax returns that result from the exclusion. ${ }^{89}$ The difference in results of our methodologies and the official estimates are depicted in Figures 7 and 8.

\section{FIGURE 7}

Grade Corrected Distribution of Tax Exempt State and local BONDS

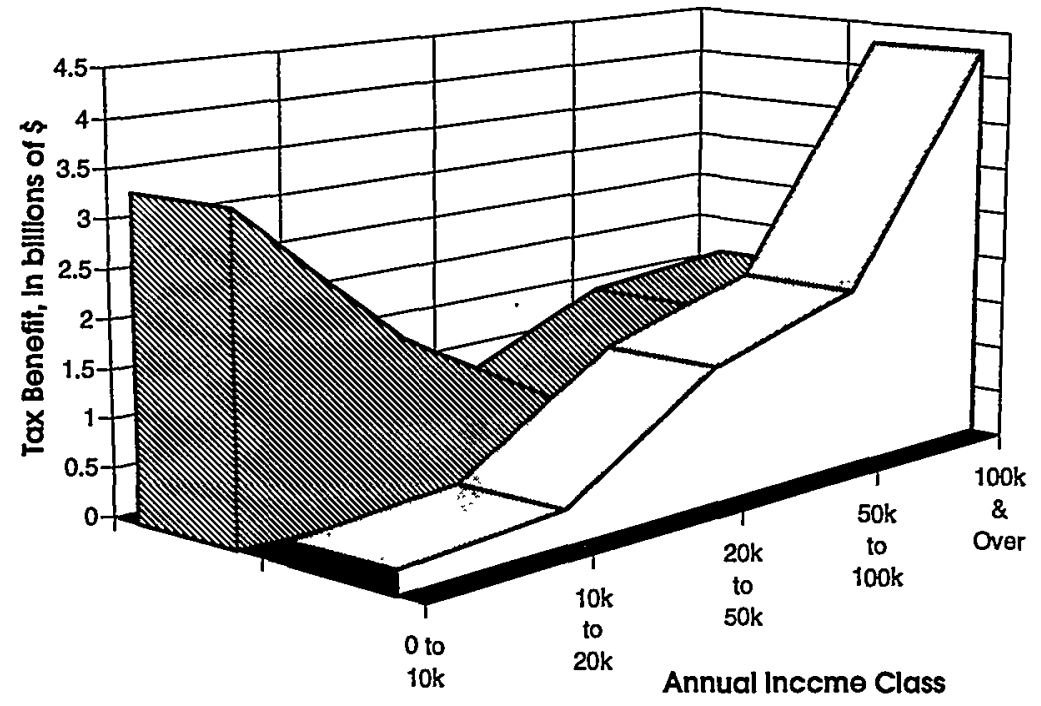

Note: The numbers for Graetz were scaled to 1990 by multiplying the percentage of total benefits for each class in Groetz, 1975, by the total amount of interest deductions in CRS, 1990.

88. See Michael J. Graetz, Assessing the Distributional Effects of Income Tax Revision: Some Lessons from Incidence Analysis, 4 J. Legal Stud. 351, 360 \& n.39 (1975).

89. See David F. Bradford, Untangling the Income Tax 243-55 (1986). 
FIGURE 8

\section{Bradford Corrected Distribution of TaX-Exempt STATE AND LOCAL BONDS}



Annual Income Class

\section{口Corrected \\ SConventional}

\section{Source: Bradford, 1986.}

Note: Numbers are for 1985.

The major revisions Bradford and I made to the standard distributions, depicted in Figures 7 and 8, reflect efforts to take into account the "price" effects of the exclusion of state and local bond interest. Price effects lower the interest rate received by the upper income purchasers of these bonds. Changes in tax rates typically will have price effects. In the case of municipal bonds, prices of such bonds increased in anticipation of and in response to the tax rate increases of the 1993 legislation.90 Martin Feldstein has argued that assessments of the equity of any tax reform should take such price effects into account and that changes in such prices due to a change in legislation should be treated as a departure from standard notions of horizontal equity. ${ }^{91}$ I have disagreed with this view. ${ }^{92}$

There are many difficult issues in evaluating how and when to take market responses, such as estimated effects on pre-tax returns, into account. Unlike actual taxes, Congress is unable to spend the changes in investors' pre-tax returns due to repeal of tax advantages-the "implicit

90. See Tom Herman, Tax Report, Wall St. J., Jan. 20, 1993, at Al. (1976).

91. See Martin Feldstein, On the Theory of Tax Reform, 6 J. Pub. Econ. 77, 94-97

92. See Graetz, supra note 73 , at 79-81. 
taxes." Congress even seems likely to have difficulties understanding the concept. It may therefore be futile for the staffs to attempt to construct distribution tables that reflect reductions in pre-tax returns even when the data are available. On the other hand, distributional tables that are as misleading as the official tables distributing the benefits of the tax exempt bond exclusion can be quite harmful when used in the tax legislative process. In this case, for example, they disguise a change that will almost certainly reduce the after-tax income of low- and middle-income taxpayers as one that affects only high-income taxpayers.

Most economists would suggest that the way out of this dilemma, in theory at least, is to perform a general equilibrium analysis and to examine changes in the distribution of after-tax income within a general equilibrium framework assuming the enactment of the proposed legislation. This would take into account effects of the tax rules on pre-tax returns both before and after the legislation. But the data demands of such general equilibrium analyses are large, the required assumptions are many, and the answers that result are sensitive not only to the limitations of data and the assumptions made but also to the structure of the general equilibrium model. Moreover, general equilibrium models typically are not capable of estimating effects of relatively small changes in policy. The mathematical elegance of general equilibrium analyses seems likely to produce a false sense of precision, even in circumstances of consensus about the general direction of change. ${ }^{93}$ Nevertheless, the "black box" quality of general equilibrium analysis is probably no more inscrutable to a legislator than the current distributional methodology, and where the nature of the change and time permit, something may be learned from engaging in such analysis. OTA, for example, has recently published results of three differing general equilibrium analyses of corporate tax integration. ${ }^{94}$ A similar general equilibrium analysis of President Clinton's health reform proposals might have been quite useful in illustrating the likely direction and perhaps even impact of such a substantial proposal for change on important economic variables.

2. Lifetime vs. Annual Income. - Recently public finance economists have embraced the view that distributional burdens of taxes (and perhaps other government actions, including expenditures) should be estimated with respect to a lifetime rather than an annual measure of income. ${ }^{95}$ Indeed, a lifetime perspective has begun to creep into the tax staffs' analysis of tax distribution. For example, $\mathrm{CBO}$ recently assessed the distribu-

93. Some of the false sense of precision would be eliminated if a range of estimatesa so-called confidence interval-were provided. Potential improvements in the legislative process resulting from presenting a range of revenue estimates are discussed infra text accompanying notes $146-147$.

94. See U.S. Dep't of Treasury, Income, supra note 78, 111-52 (1992); see also Fullerton \& Rogers, supra note 24, at 9-15.

95. See Fullerton \& Rogers, supra note 24, at 17-21; Alan J. Auerbach et al., Generational Accounts: A Meaningful Alternative to Deficit Accounting, in Tax Policy and the Economy 55, 55-56 (David Bradford ed., 1991). 
tional burdens of excise taxes on alcohol and tobacco with reference to a lifetime imcome measure, ${ }^{96}$ and JCT contends that its method of distributing consumption taxes approximates a lifetime perspective. ${ }^{97}$ But these are exceptions; generally, all three staffs distribute tax changes with reference to annual rather than lifetime income.

Classifying people and measuring tax burdens with respect to their annual income has some obvious distorting characteristics, such as classifying students and elderly people as poorer than they may be. It also emphasizes equal annual earnings rather than equal annual consumption, and as a result makes early consumers seem poorer than early earners. Econoinists have long used a life-cycle framework in explaining much of people's savings behavior, and this view of savings as a temporary postponement of consumption has been used to argue in favor of using lifetime income as an index of people's relative well-being. ${ }^{98} \mathrm{~A}$ full discussion of this issue is well beyond the scope of this Article, but, as Figure 9 below demonstrates with respect to the distribution of a broad-based consumption tax, the choice between an annual and lifetime perspective may have substantial effects on the distributions shown.

96. See Congressional Budget Office, Federal Taxation of Tobacco, Alcoholic Beverages, and Motor Fuels 2-3 (1990) [hereinafter CBO, Tobacco, Alcohol, and Fuels 1990].

97. See JCT, Measuring Tax Burdens 1993, supra note 23, at 57-58.

98. There is considerable dispute in the literature as to how much of the disparity of wealth holdings is explained by life-cycle savings. See, e.g., Atkinson, supra note 67, at 76-77. 
Figure 9

Distribution of a 5\% Broad-Based Consumption TAX

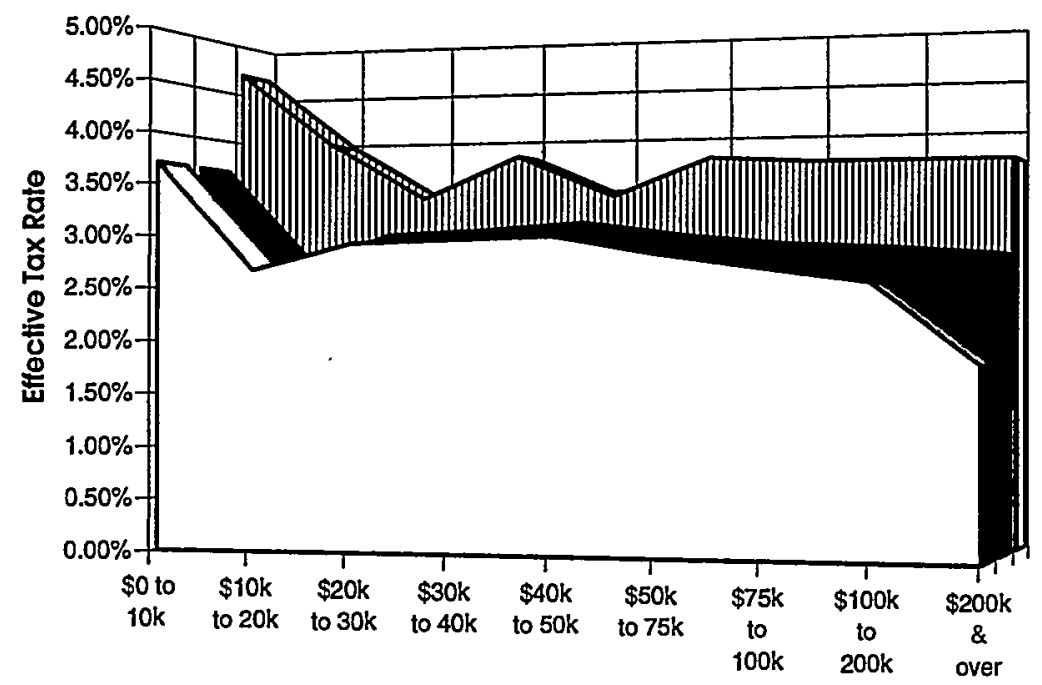

Annual Inceme Class

Sources: JCT, 1993. Caspersen \& Metcalf, 1993.

1. $(0, C)$ and $(0, Y)$ are the same distributions os those of Figure 6.

2. The VAT is distributed over lifetime income.

3. The VAI plot is an approximate mapping cf Metcalfs decile distribution Into JCT's Income classes.

First, a philosophical grounding for a lifetime basis for measuring relative well-being has yet to be fully developed, even though a lifetime perspective finds substantial support in certain fundamental philosophical concepts, including the idea that people should be responsible for their actions throughout their lives and prudent in preparing for both old age and emergencies. A lifetime view might also be defended as a better approach in advancing equality of opportunity over equality of outcome.

On the other hand, the contrary view also enjoys philosophical support. Derek Parfit, for example, contends that our future selves might better be thought of as persons different from whom we now are and that people may rationally care far more about their present than future selves, in a manner analogous to the greater care they experience for themselves than others. ${ }^{99}$ This suggests philosophical difficulties that

99. See Derek Parfit, Reasons and Persons 92-93, 190-91 (1984). 
cannot be solved by discounting future income to present values as a basis for comparing people's well-being. ${ }^{100}$

Norman Daniels grounds an argument for the equity of a lifetime perspective in public policy regarding health care in the claim that "consistent differential treatment by age will equalize over time," i.e., that the young and the old may be treated differently at any moment in time but over time people will be treated both ways. ${ }^{101}$ The validity of this argument, of course, is dependent on consistent treatment of certain age groups over a long period of time, something that no Congress can assure.

Most economists who have embraced the lifetime measure of ability to pay purposes of tax policymaking have done so without either serious argument or defense. Often it seems they have done so because they prefer consumption to income taxation (perhaps because of its lesser taxation of savings). ${ }^{102}$ However, in the absence of perfect capital markets, high lifetime income may not reflect high current ability to pay taxes, particularly when liquidity constraints are serious. Short-term precautionary savings may operate to smooth consumption over several years rather than over a lifetime.

Moreover, there are major difficulties in assessing lifetime income. First, given pervasive uncertainty about the future, discounting future estimated mcome to the present is fraught with difficulties. As a consequence, some analysts simply use annual consumption as a proxy for permanent or lifetime income, ${ }^{103}$ but it is clear that, in principle, bequests and inheritances must also be taken into account. ${ }^{104}$ However, none of the methods as yet developed for taking bequests or inheritances into account is fully satisfactory. ${ }^{105}$

In addition, particularly for lower- and middle-income persons, annual consumption may well be a better measure of a person's ability to pay taxes than her annual income. At the very top of the wealth distribution, however, this is not the case.

100. Einer Elhauge, Health Law Policy: The Moral Paradigm (1993) (unpublished manuscript on file with the Columbia Law Review).

101. Norman Daniels, Am I My Parents' Keeper?: An Essay on Justice Between the Young and the Old 41 (1988).

102. See Bradford, supra note 89 , at $148,149-54$ (advocating imposing tax burdens according to an individual's opportunities rather than according to more traditional concepts such as an individual's ability to pay).

I03. See, e.g., CBO, Tobacco, Alcohol, and Fuels 1990, supra note 96, at 2; James M. Poterba, Lifetime Incidence and the Distributional Burden of Excise Taxes, 79 Am. Econ. Rev. 325, 325 (1989) (papers and proceedings).

104. See Henry J. Aaron \& Alicia H. Munnell, Reassessing the Role for Wealth Transfer Taxes, 45 Nat'l Tax J. 119, 119 (1992).

105. See, for example, Fullerton \& Rogers, supra note 24 , at 74 , who simply assume that any inheritances received must correspond to bequests transferred, an assumption that affects only the lifetime income classification of people who receive bequests. 
Even if one regards a lifetime, as opposed to an annual or multi-year measure of income, as having significant philosophical or economic advantages, the implications of such an advantage is far from clear in the political context in which these distributional questions are being asked. As Tom Barthold of the Joint Committee Staff has pointed out, politicians do not tend to regard an individual who is making $\$ 200,000$ in a current year as having the same current ability to pay taxes as an elderly individual earning $\$ 35,000$ even if the present value of their lifetime incomes is the same. ${ }^{106}$ A person's current ability to pay is certainly relevant since taxes must be paid currently to finance government currently.

Of even greater significance, our system of government does not give one Congress the power to bind the legislation of a subsequent Congress. Therefore, it is impossible for any group of legislators to make a viable binding political commitment to fair taxation over a person's lifetime. The fact that the current Congress cannot commit the policies of future Congresses encourages self-interested people lobbying legislators to try always to maximize their present interests. This alone might well make it of special concern to legislators to know who wins and who loses in terms of their present status. In addition, it may well be appropriate, for example, that an age cohort that experiences its peak income-producing years during wartime, when higher taxes have historically been required to pay for the nation's defense, pays more in lifetime taxes than an age cohort whose peak earnings occur during peacetime, when taxes have historically been lower, even though a lifetime perspective would regard this as unfair.

Fullerton and Rogers have suggested a strong equity criterion that would require both that current taxes reflect current ability to pay and that lifetime taxes reflect lifetime ability to pay. ${ }^{107}$ Even if one embraces this criterion in principle, however, it is difficult to imagine how it would be enforced in practice. ${ }^{108}$ Even if one rejects a lifetime income measure in general, a lifetime perspective may nevertheless offer useful and important information in assessing the fairness of tax changes. First, it suggests the importance of looking at how proposed tax changes affect different age cohorts, both as a way of alerting decisionmakers to the fact that measures of current income for the young and old may understate their abilities to pay and also to raise to the level of explicit decisionmaking issues of intergenerational equity. ${ }^{109}$ Indeed, important policy initiatives-for example, a wide range of tax legislative provisions governing

106. See Thomas A. Barthold, How Should We Measure Distribution?, 46 Nat'l Tax J. 291, 292 (1993).

107. See Fullerton \& Rogers, supra note 24 , at 93 n.2.

108. Consider Figure 9 above, which shows the difference in distribution of a broadbased consumption tax using annual and lifetime income classifiers.

109. See Laurence J. Kotlikoff, Generational Accounting: Knowing Who Pays, and When, for What We Spend 115-21 (1992); Auerbach et. al, supra note 95, at 92 (predicting that future generations face approximately $20 \%$ larger net tax burdens than current newborns). 
retirement savings and income-that are troublesome from an annual perspective may well be far more justified from a lifetime perspective.110

In addition, where taxes are being imposed in an effort to induce taxpayers to shift consumption away from specific harmful items of consumption, such as alcohol or tobacco, toward a less harmful consumption mix, the fact that a tax that looks regressive on an annual basis may not be unduly problematic. Legislators should be alerted to the fact that these type of taxes may be proportional or even progressive when viewed on a lifetime basis. In addition, distributional tables do not in any way distinguish the effects of taxes such as these, which are deliberately being used to penalize or even to change undesirable behavior, from situations where taxes are simply being used to raise revenue. Figure 10 compares the effects of a cigarette tax increase to both annual income and annual expenditures (often used as a proxy for lifetime income.)

\section{FIGURE 10}

Net Increase in Cigarette Tax as a Percentage of Post-Tax INCOME AND EXPENDITURES

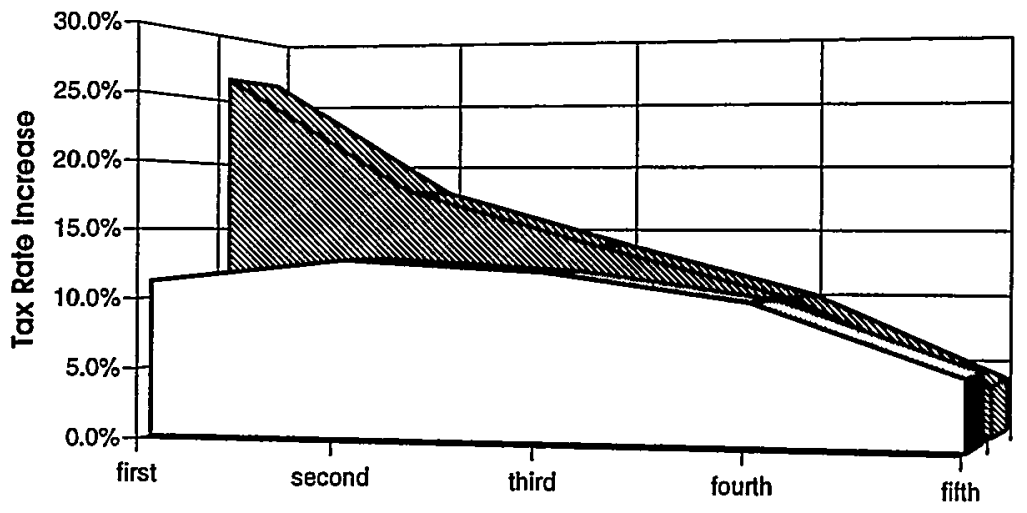

Annual Incame Quintile

DAll Expenditures

NPost-Tax Income

Source: CBO, 1990.

Note: The numbers are for 1990.

Congress may in this context want to examine the distributional burden of these taxes over a time horizon longer than one year. Studies suggest that tobacco taxes are proportional in regard to lifetime income and that alcohol taxes are slightly progressive. ${ }^{111}$ To the extent that legis-

110. See Michael J. Graetz, The Troubled Marriage of Retirement Security and Tax Policies, 135 U. Pa. L. Rev. 851, 852-55 (1987).

111. See CBO, Tobacco, Alcohol, and Fuels 1990, supra note 96, at 80. 
lators are preoccupied with making a JCT or other staff distributional table look "right," however, such legislation will be inhibited. In this case, distribution tables based on annual income tend to serve poorly the legislative process. ${ }^{112}$

Despite the staffs' virtually universal use of annual income measures, the impact of tax legislation on various age cohorts and on inter-generational equity is very important and deserves to be highlighted. More generally, the appropriate role of lifetime or multi-year income perspectives for assessing ability to pay in the political process deserves ongoing attention and debate.

3. Distributing Transfers as Well as Taxes. - All three of the staffs recognize that in distributing tax changes or existing taxes, they are presenting only a partial picture of the distributional effects of governmental actions. JCT, for example, remarks:

The full effect of government policies on the economic well-being of different groups of individuals can only be determined by examining the burdens and benefits imposed by changes in expenditure policy as well as tax policy .... The effects of ... expenditure program [s] will be ignored in the JCT distributional analysis which looks only at tax changes. ${ }^{113}$

JCT defends this practice on four grounds: (1) its staff has no particular expertise in distributing expenditures and to do so would increase considerably the work of that staff; (2) it is impossible to consider state and local governments' burdens and benefits-an objection that applies with equal force to distributing taxes alone; (3) most proposals for tax changes do not have specific expenditure changes associated with them-a claim that today seems unrealistic, particularly since most tax changes in recent years have been part of omnibus budget legislation and, in any event, is irrelevant; and (4) the policymakers who make greatest use of JCT distributional analyses are interested in isolating the distributional effects of tax changes-in other words, the staff claims to be answering only the questions that have been asked. However, given that alternatives to taxes are often used as a tool for implementing governmental policies, distributional effects of non-tax governmental action should not be ignored. The staffs' decision to do so often presents a misleading picture.

The important difference between a distribution of taxes alone and one that combines taxes and transfers is depicted in Figure 11, which shows an estimate of the distribution of both taxes and transfers from the 1992 Economic Report of the President:

112. This effect will be exacerbated by tables that distribute burdens rather than taxes. See supra Part II.C.1.

113. JCT, Measuring Tax Burdens 1993, supra note 23, at 2 (evaluating tax changes without regard to changes in expenditures). 
FIGURE 11

Effects of Taxes and Transfers on Income, 1990

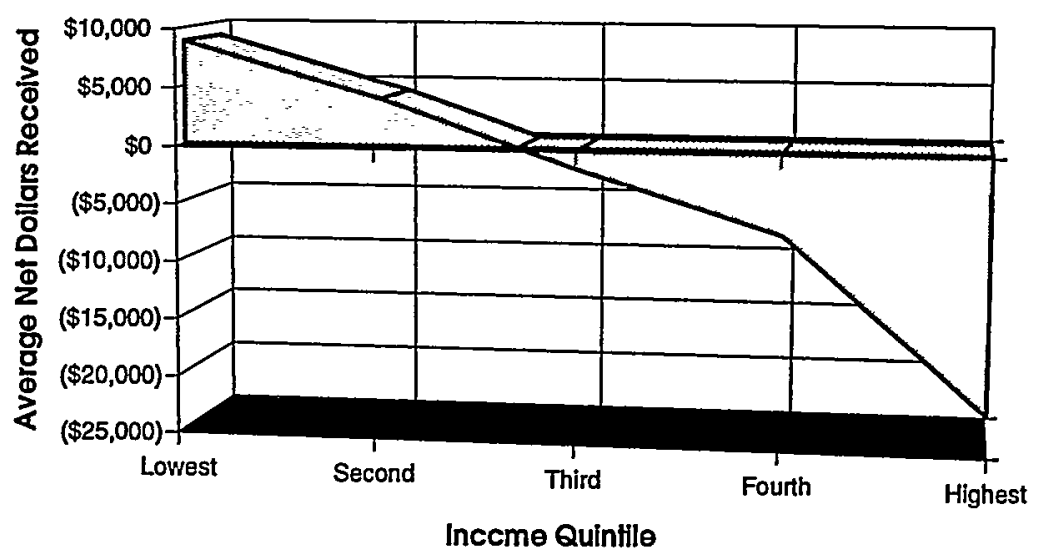

Source: CEA, 1992.

The omission of transfers from the distributional tables is especially misleading in the case of payroll taxes used to finance old age, survivors, and disability insurance benefits, and health insurance benefits under Part A of Medicare. Both of these programs were designed (and embraced by the American public) as programs of social insurance under which wage earners and their employers would make contributions through a payroll tax equal to a fixed percentage of wages (or some portion thereof) and, in exchange, would receive wage replacement retirement benefits, survivors' and disability insurance, and hospital insurance during retirement. The growth of these payroll taxes as a percentage of federal revenues is the single most striking fact in the development of the nation's tax policy in recent decades. ${ }^{114}$ Indeed, recent expressions of concern regarding increased tax burdens on middle class families over the last decade are largely attributable to the rise in payroll taxes.

As tax policy analysts know well, the Social Security payroll tax is regressive when viewed in isolation, but the Social Security system is quite progressive when benefits are taken into account. Nevertheless, estimates of the existing tax burden and of changes in tax burdens since 1977 (which is frequently used as a baseline by CBO), or since 1980 (which marks the beginning of the Reagan Administration), routinely include payroll taxes without taking into account the benefits that they finance. Figure 12 shows the distribution of social security taxes alone and Figure

114. These taxes have risen from less than $10 \%$ of total budget receipts in 1952 to nearly $40 \%$ in 1992. See generally, Graetz, supra note 15, at 21. 
13 shows the distribution of social security taxes and benefits. The distributional implications of these two pictures are quite different.

FIGURE 12

1990 Effective Social Insurance Tax Rate By Famity Quintme

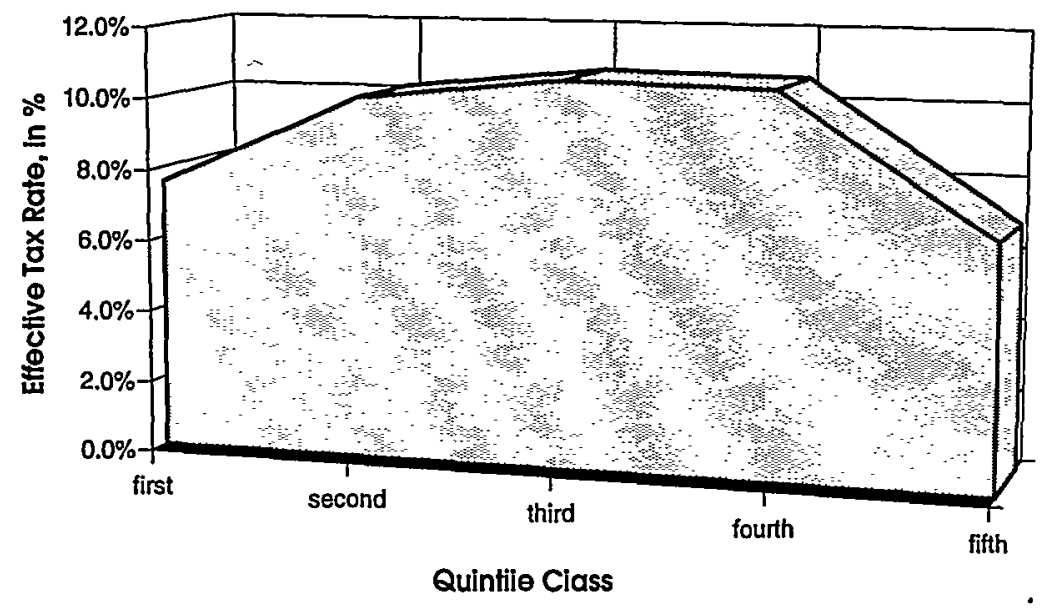

Source: $\mathrm{CBO}$. 


\section{FIGURE 13}

\section{Social Security Taxes and Net Benefits}



Annual Income Quintile

\section{DNet Taxes \\ $\$$ Taxes Pald}

Source: OTA.

1. The annual income quintiles ore based on Census money income for 1987.

2. Net toxes is equal to social securify foxes paid minus soclal security benefits recelved.

Obviously, methods of distributing the benefits of government expenditures are no less disputable or demanding of questionable judgments than are distributions of taxes or tax burdens. Indeed, many of the same questions discussed here regarding the units of analysis, income classifiers, economic incidence, and the like are present in the realm of expenditure distribution and are perhaps even more controversial. Even in answering a question limited to the distribution of Social Security benefits, there are serious issues about how best to show the combination of taxes and benefits. For example, the picture in Figure 13 above, which shows a current year's distribution of taxes and benefits, looks quite different than an analysis that examines payroll tax contributions with reference to rates of return experienced by various income cohorts. ${ }^{115}$

The one important exception to the omission of government expenditures from tax distributional tables is the inclusion of outlays under the refundable earned income tax credit ("EITC"). The most likely explanation for this practice is that EITC outlays are governed by a provision of the Internal Revenue Code, rather than other titles of the U.S. Code, but this explanation cannot be fully satisfying, even if one has come not to expect purity. 
Despite the theoretical difficulties and problems with data, ignoring government transfers in a political context is a major disservice, particularly to a nation experiencing fiscal stress due to a long-standing federal deficit problem. For example, ignoring government benefits makes it easier for politicians to promise and support middle class tax cuts in apparent sympathy for the recent increase in middle class burdens despite the well-known fact that an enormous share of federal government entitlement expenditures benefits the middle class. The share of government expenditures targeted to people at or near the poverty level is important, but far from the full story. Many government expenditures, including, for example, Medicare, Social Security retirement benefits, and farm subsidies substantially benefit middle- and even upper-income families. Distributional tables limited to taxes alone-particularly when Social Security and health payroll taxes are included-present a very misleading picture, either in the context of tax increases to fund additional spending or, vice versa, spending reductions to fund tax reductions.

4. Benefit Taxes and User Charges. - As the brief discussion of tobacco and alcohol taxes suggests, ${ }^{116}$ the reason for enacting a tax change may influence the most appropriate method of showing the distributional effects. It is difficult, and in some cases naive, simply to ignore adverse distributions in such cases. The preceding section, which emphasizes the significance of government transfers, raises particular questions for the distribution of taxes levied on the "benefit" principle, including both explicit user charges, such as entrance fees at the national parks or fees for animal grazing rights on federal lands, and other benefit-based taxes, of which federal and state gasoline taxes to fund federal highway construction and repair are today probably the most important.117 The proper treatment of these taxes is not clear. Showing the burdens without the benefits is clearly misleading, as suggested above. On the other hand, leaving these kinds of taxes out of the "distribution of current taxes" column or ignoring the distribution of changes in such taxes entirely is not an attractive alternative. This alone may suggest that providing Congress with a "distributional table" is an unfortunate oversimplification.

5. Mandates and Regulations. - Closely related to the question of distributing government expenditures or benefits along with taxes is the issue of the distributional impact of non-tax regulations and government mandates. During consideration of what was to become the Clean Air Act of 1990,118 Congressman Pete Stark (D. Calif.) of the Ways and Means Committee introduced a proposal ${ }^{119}$ for taxes based upon levels of sulfur dioxide and nitrogen oxide emissions of electric utilities in lieu of a regulatory emission permit trading mechanism that was ultimately adopted by

116. See supra text accompanying note 111 .

117. See generally Congressional Budget Office, User Charges and Benefit Taxes (1994); see also CBO, Tobacco, Alcohol, and Fuels 1990, supra note 96, at 56-58.

118. Pub. L. No. 101-549, 104 Stat. 2399.

119. See H.R. 4177, 101st Cong., 2d. Sess. (1990) (Stark bill). 
the Congress. Under standard staff practices, no distributional tables were (or would be) constructed with regard to a regulatory system controlling emissions, although there should be little disagreement that to the extent that a regulatory system imposes pollution control costs on electric utilities, those costs will generally be passed on to consumers in the form of higher electricity prices. If such an increase in electricity prices was distributed to income classes in a manner similar to that of an excise tax on electricity, the changes would be shown to have a quite regressive distribution.

Using.the tax system rather than regulation to control harmful externalities, such as pollution, would induce JCT to construct a distributional table that would depict the regressive burden of the tax change. ${ }^{120}$ Along with the public's general anti-tax sentiment and some institutional resistance to using the tax system as a regulatory device, this dramatic difference in distributional practices would tend to inhibit the use of the tax system to control externalities, even in circumstances where a tax might prove to be a better instrument of government policy. The chloro-fluorocarbon (CFCs) tax imposed by the 1989 legislation offers a good example of an effective tax enacted primarily for environmental reasons. ${ }^{121}$ Proposals for carbon taxes (or other energy taxes) as a ineans to address problems of global warming offer additional potential examples.

The issue of evaluating distributional consequences of government requireinents or mandates also occurs in connection with legislation such as the Family and Medical Leave Act of $1993^{122}$, which mandates that einployers provide certain benefits to employees. A far more significant example was President Clinton's health care reform proposal, which would have required employers to inake payments for a substantial portion of the costs for their employees' health insurance coverage. Generally, such mandated payments on behalf of employers are shifted to employees through reductions of wages. ${ }^{123}$

In testimony in February 1994, Robert Reischauer, Director of CBO, concluded that the mandate in the Clinton health care plan should be treated similarly to a tax for federal budgetary purposes. The Clinton Administration had hoped to reach a different result by requiring that einployers' and employees' mandatory payments be made directly to state

120. Recall that JCT uses the "static" revenue estimate in estimating "burden." See supra text accompanying notes 45-48. If, however, the excise tax serves to induce electricity users to internalize costs they are imposing on others, there is at least a question about whether the excise tax should be counted as a "burden" at all.

121. See Omnibus Budget Reconciliation Act of 1989, Pub. L. No. 101-239, § 7506, 103 Stat. 2106, 2364-69.

122. Pub. L. No. 103-3, 107 Stat. 6.

123. See Jonathan Gruber \& Alan B. Krueger, The Incidence of Mandated EmployerProvided Insurance: Lessons from Workers' Compensation Insurance, (National Bureau of Economic Rsearch Working Paper No. 3557), reprinted in 5 Tax Policy and the Economy 111-44 (1991). 
health alliances, instead of deposited with the Internal Revenue Service, which would then pass them on to the health alliances.

Regardless of the niceties of the administration of such mandates or their budgetary labels, it is unmistakable that a federal law that requires employers to pay a specific amount for the health insurance coverage of each of their employees places an economic burden on employee wages, with distributional consequences somewhat similar to a payroll tax. Indeed, if the amount required to be paid on behalf of each employee is a per capita amount, rather than a percentage of payroll, the distributional burden on employees would be considerably more regressive than a flatrate payroll tax.

Putting aside the (metaphysical but important) political question whether these mandates are in fact taxes, constructing any distributional table for the Clinton health care financing proposals would have been a daunting task. First, the amounts of payments required by employers and their employees were proposed to vary across regions depending on local health care costs, and the relationship of these regional variations to regional variations in wages is difficult to know. For this and other reasons, it is impossible to tell when the proposed caps on employer contributions as a percentage of payroll (never greater than 7.9 percent) would be binding under the Clinton Plan. The caps would bind for some employers but not for others and would be more likely to be binding in some regions than in others. One can hazard a guess that if JCT or OTA were asked to prepare a distributional table of the proposed Clinton Health Security Act, they would decline to do so on the grounds that the data simply do not permit fulfillment of such a task-a position similar to that taken by JCT prior to 1992 (which it has since reversed) with respect to luxury excise taxes and corporate tax changes.

Notwithstanding the difficulties of constructing a distributional table, however, the general distributional burden of President Clinton's employer-mandate financing mechanism is clear. The burdens will be borne by employees in a manner not dissimilar from the burden of payroll taxes generally, but in some instances, in a more regressive manner. Likewise, the distribution of specific tax increases on tobacco and the payroll-based "assessment" for corporations (which do not join regional alliances) is clear. If distributional tables were constructed for the Clinton health care financing system in the manner traditional for tax proposals generally, they would prove an enormous embarrassment for the President. Such tables would suggest a major middle class tax increase, which would not only contradict the President's campaign promises of tax cuts for the middle class, but would also contrast sharply with his oftrepeated insistence that at least seventy percent of the tax increases of the 1993 Budget Act be borne by people with incomes over $\$ 100,000$.

A full accounting of the distributional consequences of the Clinton health care proposals, however, would ease this embarrassment substan- 
tially, because, as I have discussed above, ${ }^{124}$ government expenditures as well as taxes should be distributed in these kinds of distributional tables. This seems particularly true in a context such as health care reform, where new taxes would be imposed to fund specific enumerated benefits. As with Social Security, combining the distributional burden of the Clinton health care proposal's mandates (or taxes) and its benefits would almost certainly convert a quite regressive financing burden into a progressive system, although there almost certainly would be some, perhaps substantial, net tax increase on families with incomes below $\$ 100,000$.

Commentators have emphasized that the Clinton health care financing scheme has been designed largely in response to widespread public anti-tax sentiment and the attendant political difficulties of enacting any broad-based tax financing mechanism. The analysis here suggests in addition that relying predominantly on a complex system of mandates also avoids the considerable embarrassment to the President that would result from the normal staff distribution tables that would be prepared by OTA, $\mathrm{CBO}$, or JCT if taxes were substituted for mandates. Even without a distributional table, of course, any of these expert staffs could describe generally the likely distributional patterns of the Clinton health care proposal.

6. Federalism. - None of the staffs distribute taxes that are imposed at the state rather than the federal level. However, many state and local governments have tied their tax systems directly to the federal system so that when federal income tax law is changed, some state and local tax burdens will automatically change as a result, unless the state government enacts specific legislation to avoid the changes. Federal tax legislation may also have less direct effects on state and local tax burdens. As suggested above (see Figure 7), repeal of the federal tax exemption for interest on state and local bonds, for example, would necessarily involve a state and local government tax response-a response that typically is ignored in distributional tables prepared by the federal tax staffs. ${ }^{125}$ Other impacts of federal tax legislation on state fiscal systems may be even less direct; for example, the repeal of the federal income tax deduction for state sales taxes in 1986 was a major factor in Connecticut's substitution of state income taxes for a portion of its state sales taxes. In this case, the federal change ultimately tended to make the state tax system more progressive.

The decision of all of the staffs to omit state tax effects seems a reasonable one, given the difficulties of doing the relevant calculations and the great variations from state to state and, in some cases, even within states. However, the picture presented in the distributional tables will be incomplete. State and local tax effects may, in some instances, be sizable, and when they are, they should be identified for policymakers.

124. See supra text accompanying notes 113-115.

125. See supra text accompanying note 88 . 
7. International Aspects. - Our nation's economy has become inextricably linked with world-wide markets and investments. But none of the staffs' distributional tables allocate any portion of proposed or enacted tax changes to foreigners, nor do the distributional tables commonly presented typically take into account changes in Americans' behavior made possible by integrated capital markets and the global economy.

Many tax proposals now advanced are intended to change the taxation of international income, sometimes focusing on the taxation of U.S. source income of foreign persons, sometimes on U.S. taxation of foreign source income of U.S. persons. Moreover, many proposals primarily designed to change U.S. tax policy may also affect substantially the U.S. taxation of foreigners or foreign income of U.S. persons. Proposals for integration of the corporate income tax and substitution of some form of broad-based consumption tax for all or a portion of either corporate income taxes or payroll taxes offer two prominent examples. Finally, international capital mobility may require different analyses of the incidence of U.S. taxes or tax incentives. CBO, for example, grounds its decision not to allocate the entire corporate income tax burden to owners of capital on the difference between an open and closed economy. ${ }^{126}$

The JCT pamphlet on distribution methodology defends its practice of ignoring the effects of U.S. tax changes on foreign persons. ${ }^{127}$ JCT's judgment not to attempt generally to estimate such effects seems reasonable, given uncertainties about how foreign governments might respond to U.S. changes and the limited current technical capacity of the staff to make such analyses. JCT also defends the omission of analysis of any impact on foreign persons on the ground that "domestic individuals or family units" are "the group with whose well being members of Congress and others are most likely to be concerned,"128_a claim that is indisputable as stated but which ignores Congress's interest in shifting tax burdens to foreigners. That JCT's approach may be reasonable does not, however, make the omission of international aspects from distributional analyses any less important.

Far more questionable is JCT's decision to ignore foreign income taxes, but not foreign source income, of U.S. persons in its distributional tables. ${ }^{129}$ To the extent that foreign taxes have been imposed on such income and U.S. taxes have been eliminated through the foreign tax credit, this practice has the effect of greatly understating the tax burden

126. See Congressional Budget Office, The Changing Distribution of Federal Taxes; 1975-1990, 22-23 (1987); cf. Jane G. Gravelle, Corporate Tax Incidents in an Open Economy, 1993 Vol. of the Proc. of the Nat'l Tax Ass'n 173 (1994) (contending corporate taxes are borne by capital even in an open economy with global capital markets).

127. See JCT, Measuring Tax Burdens 1993, supra note 23, at 78-81 (justifying practice primarily on grounds of practicality of calculation).

128. Id. at 81.

129. See id. at 109-10; Joint Committee on Taxation, Summary of the Revenue Provisions of the Omnibus Budget Reconciliation Act of 1993 (HR2264), at 109 (1993). 
on U.S. persons who earn foreign source income relative to people who earn only domestic source income. JCT's treatment of foreign source income and foreign income taxes also has the general effect of decreasing the effective tax burden that is shown for high-income people, since more foreign source income is earned by people in the upper-income brackets. The inconsistency of the JCT decision to ignore foreign taxes while claiming to reflect welfare losses or changes in "burdens" in its tables is particularly striking. As more and more people expand their investment portfolios to include foreign source income, the incompleteness of distributional tables as a result of ignoring international aspects will grow in significance.

\section{E. A Preliminary Conclusion Regarding Distribution Tables}

The problems of distributional tables detailed above make clear that they are often misleading. The relevant staffs disagree over the incidence of certain taxes, the taxpaying unit to be evaluated, the appropriate measurement of income, and even the meaning of distributing a change in taxes. In principle, there is nothing wrong with such disagreements. They generally reflect reasonable, but different, judgments by the various staffs about controversial questions of theory as well as about the best compromise between theoretical purity, limitations of data, and public and politicians' understanding. Even within the same staff, however, compromises are not made consistently. JCT, for example, emphasizes understanding and practicality over theory in its income measure and in its family classifier, yet attempts to achieve greater theoretical purity in distributing "burdens" rather than actual taxes. OTA has reached the opposite judgment on all three of these issues, although with regard to the question of distributing tax changes or "burden" changes, there seems to be a disagreement over the best answer even in theory. When more than one staff is involved in the process of estimating distributional aspects of tax changes, or even when only one staff is involved but its personnel changes at frequent imtervals, as now seems to be the case at both JCT and OTA, judgments will vary from staff to staff and even within the same staff over time.

Areas of staff agreement seem to be no less important or controversial in the construction of distributional tables than the areas of disagreement. These include the decision to use an annual rather than lifetime (or some intermediate period) income measure, the oinission of government expenditures, regulations and mandates from distributional analyses, the omission of state and local taxes, and the failure to take into account foreign taxes. Whether the staffs agree or disagree on particular issues, the precision reflected in tables of the distributional effects of changes in the tax law is false and potentially misleading.

In my opinion, distributional tables should be abandoned as a basis for legislative decisionmaking while legislation is being drafted. Their current capacity to constrain policy decisions disadvantages the tax legis- 
lative process. The typical economist's response to empirical uncertainties-producing a range of estimates or indicating confidence intervalsis an inadequate response to the fundamental inadequacies of these tables which I have detailed here. .Politicians, journalists, and the public are incapable of reaching informed and consistent judgments about the compromises that should be made among the relevant variables; even if they were capable of such judgments, there is no reason to expect any more agreement or better results from those groups than from the professional staffs. The distributional tables that the staffs produce, however, create the illusion of precision. They endeavor to tell policymakers precisely how much change in taxes (or "tax burden") is anticipated to be experienced by people at various income levels; they appear to predict within one-tenth of one percent changes in effective tax rates that are expected to result.

In practice, if a particular distributional result is desired by powerful politicians or if a particular distributional outcome is regarded as unacceptable by these politicians, two consequences seem likely. First, one staff's methodology must dominate the process. In recent years, that staff has been JCT. Perhaps this is because the Democratic majority in Congress preferred its results to those of the Treasury during the Republican Administration. Second, important policy decisions and tax law changes will turn on the dominant staff's distributional analysis. Clearly, JCT's decision to provide policymakers with tables that distribute tax burdens rather than estimated tax changes inhibited, perhaps even defeated, a capital gains reduction during the period 1989-1992. I do not wish to debate here whether capital gains tax cuts are good or bad as a matter of policy, but only to insist that distributional tables grounded in staff judgments, which at a minimum are controversial, should not be playing such a substantial role in the tax legislative process. ${ }^{130}$

To take but one other example, in 1990, rumors were rampant that the earned income tax ("EITC") provisions of the 1990 Act were changed at the last moment to reduce the adjustments in the amount of credits for family size in order to change a distributional result in the JCT tables that turned largely on that staff's use of tax return filing units rather than families as the distributional classifier, and on its selection of distribution classes and their breakpoints. I do not wish here to dispute JCT's choice to use that income classifier or the breakpoints it has chosen (nor does it really matter whether the EITC policy was in fact changed in the way described). The important point is that it was certainly plausible to those involved in the 1990 Act that the EITC policy might have been revised solely in order to reach (or avoid) a particular distributional result in the tables. If this in fact happened, it undermined basic policy agreements that had been made over the course of a year's debate about the use of

130. I say similar things about revenue estimates in Part III of this Article. 
earned income tax credits to subsidize child care. ${ }^{131}$ Regardless of one's view about the merits of particular tax changes, this is no way to make policy decisions. The false precision of distributional tables, however, has had and in the future seems likely to have precisely that influence.

\section{II. Revenue Estimates}

\section{A. Overview of the Revenue Estimating Process}

In this Part, I briefly discuss the political uses of revenue estimates and recommendations for potential improvements in the revenue estimating process. My principal intention is to make clear the relationship and the differences between the distributional and revenue estimating processes and to identify the major problems that have emerged with regard to revenue estimating.

Unlike the distributional issue, the problems created by the central role of revenue estimates in the tax lawmaking process have been lamented elsewhere. ${ }^{132}$ Indeed, something of a consensus seems to have emerged in the academic literature about needed improvements in the production and use of revenue estimates. As a result, my treatment of this issue here can be relatively brief. My goals in this section are simply to demonstrate congressional willingness-even determination-to be bound by meaningless or, in some cases misleading, numbers, to illuminate the shortcomings of existing revenue estimating practices, and to identify proposed solutions.

In general, an estimate of the revenue consequences of a proposed change in tax law is simply a staff's best estimate of the difference between federal receipts with and without the changes in law for each year of the budget period. The estimate of receipts without the proposed change is the baseline receipts forecast, which is based upon an assumed level of certain macroeconomic variables, including Gross Domestic Product (GDP), the overall price level, interest rates, total employee compensation, total domestic investment, and the total level of state and local taxes. ${ }^{133}$

Revenue estimates, like distributional tables, hold these macroeconomic variables constant, but revenue estimates do take other rele-

131. The 1990 expansion of the EITC had been considered as a part of child care legislation by the House in 1990. Both the House child care legislation and the Senate version of the 1990 Budget Act included larger family size adjustments in the EITC than were finally adopted. See generally OBRA 90, supra note 5; H. R. Conf. Rep. No. 964, 101st Cong., 2d Sess. (1990), reprinted in 1990 U.S.C.C.A.N. 2740.

132. See Alan J. Auerbach, Public Finance in Theory and Practice, 46 Nat'l Tax J. 519, 519-26 (1993); Emil M. Sunley \& Randall D. Weiss, The Revenue Estimating Process, 11 Am. J. Tax Pol'y, 261, 265 n.6 (1992); see also Boris I. Bittker, Erwin N. Griswold Lecture, 11 Am. J. Tax Pol'y 213 (1994); Harry L. Gutman, Chief of Staff, Joint Committee on Taxation, Address Before the New England Tax Institute (April 25, 1992) [hereinafter Gutman], available in LEXIS, Fedtax Library, Taxtxt File.

133. See Sunley \& Weiss, supra note 132, at 265 n.6. 
vant behavioral changes into account. For example, revenue estimates are based upon estimates of the increase or decrease in tobacco consumption expected to occur in response to changes in tobacco tax rates; they take into account increases or decreases in capital gains realizations expected as a result of changes in capital gains tax rates. Holding macroeconomic variables constant when estimating revenue effects has long been controversial. ${ }^{134}$ Holding such estimates constant eliminates a range of disputes over the consequences of proposed legislation, facilitates comparisons of various proposed changes, and makes tax projections consistent with budgetary estimates of spending proposals. The public finance economist, Alan Auerbach, who recently served as Deputy Chief of Staff of JCT, which is responsible for revenue estimating for the Congress, has remarked that the opposite course-incorporating estimates of macroeconomic effects of tax legislation-" "places the estimator in the very uncomfortable position of having to claim confidence in an estimate in which no sensible person could have much confidence."135

Nevertheless, significant tax changes are likely to affect these macroeconomic variables, and if these effects are large, they could change the size of the revenue estimate and in some cases even whether the revenue estimate is predicted to raise or lose revenue. Changing the process for revenue estimating would no doubt raise similar questions with regard to spending estimates. On balance, holding macroeconomic variables constant when tax reductions are being considered is the more conservative course and generally protects to some extent against rosy scenarios. Not taking predicted macroeconomic effects into account in revenue estimating, however, remains quite controversial, especially when large changes, such as health care reform, are under consideration.

The seemingly straightforward starting point for revenue estimatesthe baseline forecast of receipts without the proposed changes in law-is itself somewhat ambiguous, particularly when current law is in dispute or is otherwise unclear. The tax treatinent of purchases of intangible assets, such as business goodwill or customer lists, offers a recent instance. ${ }^{136}$ In 1993, when Congress was considering changing the tax treatinent of purchases of intangibles, the Supreme Court decided Newark Morning Ledger Co. v. United States, ${ }^{137}$ a case involving the taxation of newspaper subscription lists-a customer-based intangible asset. The Court's determination of the current law treatment of this intangible asset might have had a substantial effect on the estimate of baseline receipts and, as a result, caused a change in the revenue estimates of proposals for changing

134. The 1994 election of Republican majorities in the House and Senate has renewed interest in the issue. See, e.g., Leader Chosen for Congress. Budget Office, N.Y. Times, Feb. 11, 1995, at A9; R.C. Loryworth, Debate: How to Keep Score on a Tax Cut?, Chi. Trib., Jan. 15, 1995, at C1.

135. Auerbach, supra note 132, at 523; see also Gutman, supra note 132.

136. See 26 U.S.C. $\$ 167$ (a) (1988).

137. 113 S. Ct. 1670 (1993). 
the law. Indeed, before the Court's decision in the case, a fourteen-year amortization period for purchases of intangible assets, including goodwill, had been estimated to be revenue-neutral; after the decision, enactment of the fourteen-year amortization was estimated to raise more than one billion dollars during the period 1994-1998. ${ }^{138}$ Likewise, in 1993, Congress clarified the law regarding the treatment of certain losses of savings and loan associations. Here the change in law was estimated principally to speed up two to three billion dollars in revenues that otherwise would have been realized in subsequent years. But this estimate was based on the revenue estimators' assumption that the government's litigating position would ultimately prevail; if the revenue estimators had discounted the government's litigating position or dismissed it as unlikely to be successful, substantially greater revenue would have been attributed to the change in law.

The most difficult aspect of revenue estimating is anticipating changes in behavior that will be induced by changes in the tax law. During 1989, 1990 and 1991, differences between the judgments of JCT and Treasury revenue estimators about the likely behavioral responses of people in realizing capital gains in response to lowered tax rates became a revenue estimating cause celebré. During the five-year budget period, relatively small differences in the two staffs' behavioral assumptions produced more than a twenty billion dollar swing in projected revenue effects of a proposed exclusion from income of thirty percent of capital gains. For the years 1990-1995, Treasury estimated in 1990 that the proposal would increase revenues by $\$ 12.5$ billion, while JCT estimated a decrease of nearly $\$ 11.5$ billion. Virtually all of this gap was due to differences in assumed behavioral responses: first, Treasury assumed a short-run elasticity of 1.2, JCT 1.1:139 second, Treasury assumed a long-run elasticity of 0.8 , JCT 0.66; and finally, Treasury thought it would take three years to reach the long-run, JCT only two years. ${ }^{140}$ Most economists would not view the existing empirical evidence as sufficient to choose confidently between these assumptions, but such small differences in assumed behavioral responses can, and did, have large effects on the revenue estimates. 141

138. See Full Text of W\&M Committee Report for H.R. 2141: Revenue Estimates, Tax Notes Today, May 20, 1993, available in LEXIS, Fedtax Library, Taxtxt File (offering estimate of $\$ 2.097$ billion, reflecting revisions after Newark Morning Ledger v. U.S.).

139. See Sunley \& Weiss, supra note 132, at 285.

140. See id. at 286.

141. See Staff of the Joint Comm. on Taxation, 102d Cong., $2 \mathrm{~d}$ Sess. Discussion of Revenue Estimation Methodology and Process 6-7 (Comm., Print 1992); Staff of the Joint Comm. on Taxation, 101st Cong. 2d Sess., Explanation of Methodology Used to Estimate Proposals Affecting the Taxation of Income from Capital Gains 4 (Comm. Print 1990); Sunley \& Weiss, supra note 132, at 286; Infighting Over Revenue Estimates: The Capital Gains Debate, Tax Notes Today, April 23, 1990, available in LEXIS, Fedtax Library, Taxtxt File. 
The anticipated revenue loss from the 1981 universalization of eligibility for tax-favored individual retirement accounts ("IRAs") has become a notorious example of a grossly underestimated change, attributed largely to the estimators' failure to anticipate the mass marketing of IRAs by banks and other financial imstitutions. ${ }^{142}$ When revenue estimators aggregate a large number of individual revenue estimates for specific changes to predict the overall revenue effect of a piece of tax legislation, they often claim to rely on their patron saint, "St. Offset," who they hope will assure that their errors are not all in the same direction but will instead tend to offset one another, resulting in an acceptable overall prediction and error rate. ${ }^{143}$

Commentators have long recognized that revenue estimates differ in reliability, depending on both the quality of data available to the revenue estimators and the difficulty of predicting how the change will be perceived and acted upon by taxpayers. ${ }^{144}$ No one denies, for example, that a revenue projection for imcreases or decreases in the personal exemption for the blind is far more reliable than an estimate of the revenue change from enacting or repealing special tax allowances for particular kinds of investments. ${ }^{145}$

More than two decades ago, in the first law review treatment of revenue estimating, I urged that revenue estimators "supply a range of estimates," the size of which would "provide insight into the reliability of the estimate," and that Congress should establish "categories" for revenue estimates depending on their likely accuracy. ${ }^{146}$ I came to call these categories "green light" estimates, estimates that lawmakers could proceed to use with a high degree of confidence; "yellow light" estimates, which should be used with caution; and "red light" estimates, the reliability of which was so uncertain that they should not be used at all. More recently, public finance economists who have participated in the tax legislative process have also called for a range of estimates. For example, Alan Auerbach has complamed that "existing rules and institutions leave no room for confidence intervals (which indicate the range of variation in the estimates that cannot reasonably be ruled out), the normal method of indicatimg the degree of statistical uncertainty."147

One opponent of requiring the staffs to provide revenue estimates with a range or confidence interval of their statistical reliability is Bernard Schmidtt, the JCT staff inember currently responsible for revenue estimates, who contends that such ranges "would only add additional com-

142. See Sunley \& Weiss, supra note 132 , at $283-84$.

143. See id. at 285.

144. See Michael J. Graetz, Reflections on the Tax Legislative Process: Prelude to Reform, 58 Va. L. Rev. 1389, 1417-20 (1972).

145. See id.

146. Id. at 1422.

147. Auerbach, supra note 132 , at 520 (citation omitted). 
plexity." ${ }^{48}$ Another opponent, Howard Nester, a former head of revenue estimating for Treasury, asserts that "you cannot give politicians a range" because it would inhibit their ability to "put it together and come up with a coherent range." 149 Given the tendency of congressional decisionmakers to enact complex and otherwise indefensible legal rules simply in order to make revenue estimates "come out right," this latter argument against supplying a range for estimates-grounded in its potential inhibiting effect on legislators-may well be a cogent argument on its behalf.

\section{B. Asking the Wrong Question}

Routine congressional reliance on estimates of questionable reliability has been compounded by Congress' insistence on grounding parliamentary objections during consideration of legislation and, in some instances, even legal compliance with general budgetary requirements, on predictions of changes in revenues for each year of a five-year budget period. Beginning with the enactment in 1985 of the Gramm-RudmanHollings Budget Act, ${ }^{150}$ estimates of the annual revenue effects of legislation directly triggered sequestration, a series of across-the-board spending cuts. This central role for revenue estimating continued through the 1987 Amendments of Gramm-Rudman ${ }^{151}$ and was, if anything, enhanced by the sso-called pay-go requirements of the 1990 Budget Act which linked sequesters of "entitlement" spending-spending on such things as Medicare, Medicaid, and farm price supports-to five-year estimates of the annual revenue effects of tax legislation. The amendments also required that any provisions that are estimated to lose revenue in any year of the budget period must be offset by revenue-gainers of a maguitude equal to the forecasted loss. ${ }^{152}$ This basic mechanism of the 1990 Act remains in force, but the Senate has expanded the relevant period for revenue estimates from five to ten years in some circumstances. ${ }^{153}$

There is no need to describe further the arcana of this budget legislation, simce my limited point is that Congress has mistakenly elevated the siguificance of estimates of annual revenue effects of tax legislation for

148. Bernard A. Schmitt, Commentary, 10 Am. J. Tax Pol'y 299, 303 (1992).

149. Howard W. Nester, Commentary, 10 Am. J. Tax Pol'y 303, 305 (1992).

150. Balanced Budget and Emergency Deficit Control Act of 1985, Pub. L. No. 99177, § 251, 99 Stat. 1037, 1063-72.

151. 1987 Amendments to Gramm-Rudman, Pub. L. No. 100-203, § 8001-05, 101 Stat. $1330,1330-280-83$.

152. See OBRA 90, supra note 5 , at $\$ 13101$.

153. See S. Con. Res. 63, 103d Cong, 2d Sess. (1994); see also Senate Passes Budget with IRS Compliance Amendment, Tax Notes Today, Apr. 4, 1994, available in LEXIS, Fedtax Library, Taxtxt File (transcript of debate on S. Con. Res. 63). Indeed, the proposed constitutional amendment to require balanced budgets, passed by the House but narrowly rejected by the Senate in 1995, was grounded in estimates of government receipts and spending. See Andrew Taylor, Budget Amendment's Fate Hinges on a Handful of Democrats, 53 Cong. Q. 355, 358 (1995). 
each year of a five- or ten-year budget period by tying potentially serious spending and tax consequences to these numbers. A politician therefore is behaving quite reasonably-given these constraints-when her dominant concern in considering tax legislation is making the revenue numbers "come out right." The diminished capacity of the traditional normative concerns of taxation-fairness, economic efficiency, and simplicity-to influence legislation in this context is not surprising.

Nor should it be surprising that the revenue estimates themselves have taken on increased significance, or that legislators have become experts at playing revenue estimating games in an effort to achieve the legislative outcomes they desire. A few examples of such revenue estimate games should suffice to illustrate the potential aberrations from accounting for revenues on an annual cash-flow basis within a specified budget period. Generally, these games involve accepting long-term pain to achieve short-term gain.

First, cash-flow "budget window" revenue estimates greatly influence the design of tax provisions. For example, the close relationship between investment tax credits, expensing of assets, and accelerated depreciation is well known in the tax policy literature. ${ }^{154}$ Reasonably sophisticated analysts, for example, can construct proposals for accelerating depreciation, partial expensing of assets' costs, or investment tax credits that are equivalent tax reductions in terms of their present value, but that involve quite different timing of the tax reductions and therefore have very different impacts on annual revenue estimates during a budget period. ${ }^{155}$ The following graph illustrates various potential revenue effects of one such possibility:

154. See Alvin C. Warren, Jr., Accelerated Capital Recovery, Debt, and Tax Arbitrage, 38 Tax Law. 549, 549-50 (1985).

155. For an example of such an analysis, see Jane G. Gravelle, Estimating Long-Run Revenue Effects of Tax Law Changes, 19 E. Econ. J. 481, 481 (1993) (discussing JCT's refusal to estimate revenues beyond "revenue horizon" because figures would be too "uncertain"). 


\section{FIGURE 14}

Revenue Loss From Investment Subsidies

Per Dollar of Original Investment Times Tax Rate

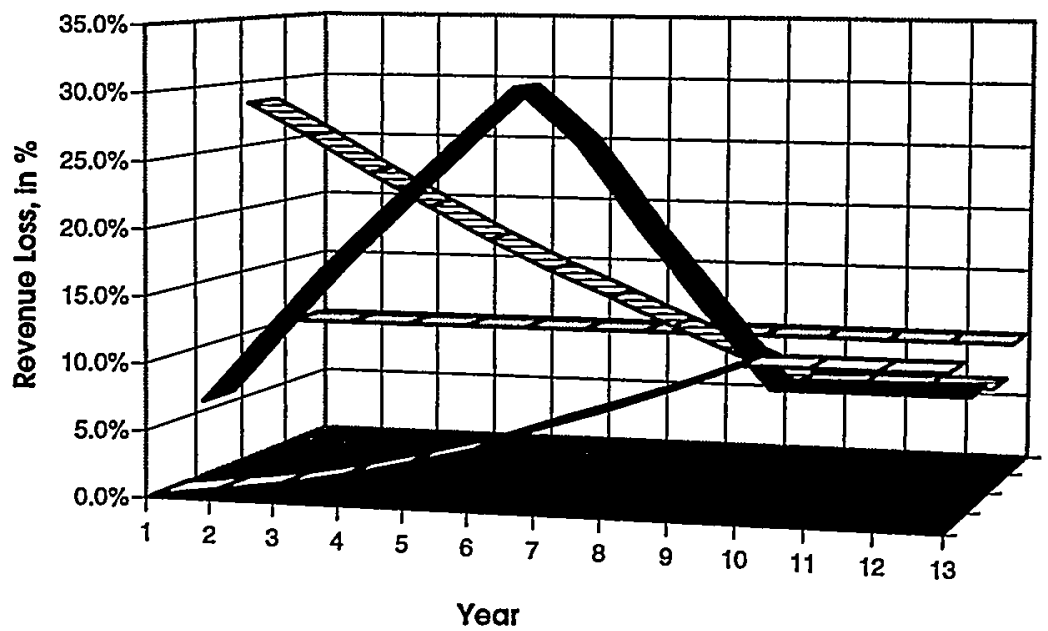

\begin{tabular}{|ll|}
\hline$\square$ Indexing & accelerate \\
日Expense & $\square$ Credit \\
\hline
\end{tabular}

Source: Gravelle, 1993.

A related phenomenon occurs with respect to the choice between "front-loaded" and "back-loaded" savings mcentives. With respect to the former, the taxpayer deducts the cost of the investment when made, accumulates investment income tax-free, and pays taxes when the funds are withdrawn. In the latter case, the taxpayer gets no deduction for putting the funds in the savings account, accumulates investment income taxfree, and pays no tax when the funds are withdrawn. When interest and tax rates are constant over time, the present value of the revenue cost of these two approaches is the same, but the pattern of revenue effects is quite different. ${ }^{156}$ Front-loaded savings accounts have large revenue costs in the years of savings; back-loaded accounts cost substantial revenues in the years of withdrawal. During the period 1989-1994, proposals to restore the universal IRA, which had been repealed by the 1986 Tax Reform Act, often took the back-loaded form, principally because the delayed revenue costs did not occur in the budget window, and, therefore, under the Budget rules, neither triggered spending cuts nor re-

156. See JCT, Revenue Estimation 1992, supra note 45, at 8-9; Gravelle, supra note 155 , at 490 . 
quired offsetting tax increases. ${ }^{157}$ The graph that follows illustrates the differences in revenue patterns of IRAs of equal present value.

FIGURE 15

Revenue Cost of Individual Retirement Accounts As a Percentage of Initial Investment (constant incomes)
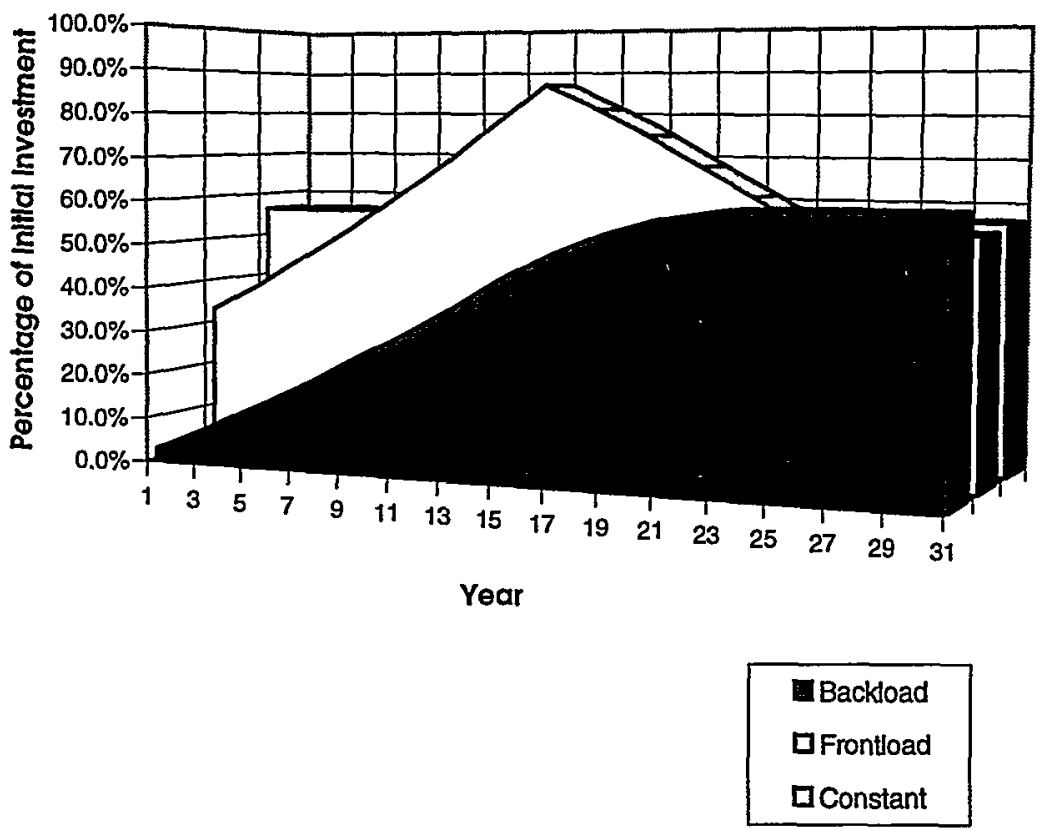

Source: Gravelle, 1993.

Probably the most venerable technique for taking advantage of cashflow revenue estimating is the "speed-up." A speed-up simply moves revenues that would otherwise be collected in a later year to an earlier year. The last year that the federal budget was in surplus was 1969-a surplus that was made possible in part by changes in rules for the deposit of withheld income and payroll taxes, so that revenues that otherwise would have been collected in fiscal year 1970 were moved into 1969.158 More recently, Congress's favorite speed-up has been accelerating collections of required estimated tax payments from individuals and corporations. Extraordinarily complex individual estimated tax provisions were adopted in 1991 solely to accelerate revenues to "pay for" extensions of unemploy-

157. See id. For various IRA proposals, see Senate Continues Budget Debate, Tax Notes Today, Apr. 8, 1994; Summaries of Today's Important Tax Items, Tax Notes Today, Nov. 13, 199I; Text of McIntyre's Testimony Before Ways and Means is Available, Dec. 18, 1991 (testimony of Citizens for Tax Justice), all available in LEXIS, Fedtax Library, Taxtxt File.

158. See 35 Fed. Reg., 19,114-15 (1970). 
ment benefits. ${ }^{159}$ Here, the temporary revenue gain was used only to pay for a temporary increase in spending, but budget rules permit using such a temporary gain to pay for a permanent revenue loser. This occurred, for exaunple, in the provisions enacted in 1994 for financing the tariff reductions of the GATT Uruguay Round Agreements Act; the most extreme example was the speed up of deposits of certain excise taxes from a due date in October to an earlier fiscal year by requiring these taxes to be deposited on September 29.160

Probably the most egregious use of budget scorekeeping rules to finance permanent tax reductions with temporary revenues is the sale of government-owned assets to pay for permanent tax changes. It is obvious that the revenue losses from the tax reductions will continue to decrease receipts long after the proceeds from the asset sale have been spent.

As a final example of revenue estimating gamesmanship, consider the creative use of temporary (or expiring) provisions. Budget scorekeeping rules, along with revenue estimating conventions, allow Congress to enact "temporary" tax increase provisions and then to count as revenue gains subsequent extensions of the temporary provision. This occurs because the "baseline" estimate of receipts does not include revenues from the expiring tax increase. As long as the temporary provision does not fund a special budgetary "trust fund," the revenue loss from the expiration of the tax does not "score" for revenue estimating purposes and the additional revenues from the extension can thus be spent on other revenue losing enactments. Obviously, this gaine increases deficits by allowing the spending of money that should have gone into the receipts baseline. Recent examples of this phenomenon are legion; they include extensions of the 1990 Act increase in the gas tax, ${ }^{161}$ the 1990 Act phaseout of personal exemptions, ${ }^{162}$ and the limitation on itemized deductions contained in the 1990 Budget Act. ${ }^{163}$

A variety of sensible proposals have been offered to make revenue estimates more meaningful. For example, estimating the effect of proposed changes on the present value of revenues collected from current taxpayers might limit the likelihood that Congress could offer taxpayers an overall tax reduction in exchange for accelerating their tax payments. Jane. Gravelle of the Congressional Research Service has recently proposed "annuitizing" the revenue effects of alternative policy proposals to

159. Emergency Unemployment Compensation Act of 1991, Pub. L. No. 102-164, $\$ 403,105$ Stat. 1049, 1062 (codified at 26 U.S.C. 6654 (1991).

160. Uruguay Round Agreements Act, Pub. L. No. 103-465, §712, 108 Stat. 4869, 4999-5001 (1994) (amending 26 U.S.C. $\$ \S 5061,5703,6302$ ).

161. See OBRA 93, supra note 6 , at $\S 13241$ (a). The $\S 13241$ (a) tax of $6.8 \%$ reflects a continuation of the 1990 nickel tax, half of which (i.e. 2.5ф) was to be used for deficit reduction, and half of which was to be used for the Highway Trust Fund. The 1993 Act added 4.36 to the $2.9 \%$ used for deficit reduction, for a total of $6.8 k$.

162. See OBRA 90, supra note 5 , at $\$ 11104$.

163. See id. at $\S 11103$. 
facilitate more appropriate comparisons of alternative proposals. ${ }^{164}$ This approach would convert any tax proposal, regardless of its effects on the federal government's cash flow, into the equivalent of an annuity, thereby putting proposals with different cash patterns on an equal footing. The Gravelle proposal would treat tax provisions in a manner more consistent with the budgetary treatment of government loans after the 1990 Budget Act.

To be sure, both of these suggestions offer potential improvements in the process and could be coupled with providing ranges of revenue estimates and classifying estimates according to their likely reliability. ${ }^{165}$ Moreover, by supplying decisionmakers with complex additional numerical information and, at the same time, by identifying uncertainties in the numbers provided to them, lawmakers would be hindered in their ability to tie legislative decisions to easy summations of revenue estimates.

But we should not be overconfident about the ability to specify procedures that will make revenue estimates routinely reliable or meaningful. Alan Auerbach, in a recent examination of the U.S. fiscal situation, has shown that a combination of "technical" and "economic" forecasting errors have, over a long period of time, made receipts forecasts excessively optimistic. Auerbach has found that CBO projections of receipts in the final year of its annual five-year forecasts have been substantially greater than those that occurred and that deficit forecasts "have proved very inaccurate and overly optimistic." 166 Moreover, there are multiple dimensions of budget and fiscal policy that would change the answers that may be considered important. For example, suggestions have been advanced to move from cash accounting to capital budgeting, to look to the full employment deficit rather than the current cash deficit, and to use inter-generational accounting as a substitute for deficit accounting. ${ }^{167}$ Whatever the scorekeeping rules, however, opportunistic and creative legislators and their staff will work within and around them, structuring proposals to maximize the likelihood of outcomes they desire.

To be sure, legislators need to be aware generally of the size and direction of revenue effects of proposals under consideration and of enactments. But permitting uncertain and frequently meaningless revenue estimates to serve as a straightjacket on policy outcomes, as they have in the past decade, inhibits thoughtful tax policymaking and undermines public respect for both the laws that result and the lawmakers that enact them.

164. See Gravelle, supra note 155, at 490-94; see also R.A. Zaldivar, Panel Spends $\$ 1.9$ Million in Futile Quest for Benefit Reforms, Phila. Enquirer, Dec. 15, 1994, at A16 (suggestion by Senator Bob Kerry to project deficit effects over a 30-year period).

165. See supra text accompanying note 133.

166. See Alan J. Auerbach, The U.S. Fiscal Problem: Where Are We, How We Got Here and Where We're Going, Working Paper No. 4709 (National Bureau of Economic Research, 1994).

167. See Auerbach, supra note 95. 


\section{ConCLUSION}

It seems impossibly difficult to communicate even the simplest facts about tax and fiscal policy to the American public. One cannot be entirely certain whether this is because politicians are engaged in willful distortions, because the politicians themselves simply do not know the facts or are misinformed, or because, as I have demonstrated here, the truth in matters of this sort is at best elusive, and often unknowable. The most recent important illustration of public confusion about fiscal "facts" was the dispute over the proportion of tax increases and spending cuts in the 1993 Act. A wide variety of estimates was offered as truth by opposing politicians. Indeed, even the experts had difficulty in sorting through the data. ${ }^{168}$ Much of the difficulty in this particular debate stemmed from routine staff practices. For example, CBO's normal budgetary treatment of user charges as "negative outlays" rather than as taxes no doubt encouraged the Clinton Administration to extend this notion by counting as spending reductions incoine tax increases on Social Security benefits. As the analysis above makes clear, distributional facts are subject to similar debate and misunderstanding.

Moreover, the precision of distribution tables is itself illusory even if they could be readily understood. Even the least disputable distributional estimates are, as Boris Bittker would put it, somewhat fanciful. ${ }^{169}$ It is natural, for example, to read Table 1 to imply that the provisions of the 1993 Budget Act will change the average tax rate on people with $\$ 40$ $\$ 50,000$ of income from $20.9 \%$ to $21.19 \%$. But as this Article has demonstrated, this is an erroneous reading of the table itself and, in any event, suggests far more precision than is plausible. The footnotes to the table make clear that the interpretation of the foregoing sentence is wrong despite the appearance of the table, ${ }^{170}$ and the discussion above makes it clear that one should not attempt to connect these two numbers since the first is an estimate of the relationship of taxes to income while the second is derived from mistakenly adding an estimate of changes in "burden" to an estimate of taxes. ${ }^{171}$

Unfortunately, the answers to distributional questions provided by these kinds of tables are probably most accurate (or, inore precisely, least inaccurate) when they are of least interest, namely, when the change is narrowly targeted or very small. To know the distributional effects of significant changes in tax policy on after-tax incomes, for example, we would have to know the effect of both the tax increase (or decrease) and any accoinpanying spending increases (decreases) and/or borrowing or

168. JCT Differs from White House in Revenue Estimates of Rate Hikes, International Enforcement, Other Provisions, Mar. 4, 1993; see also Bentsen Sought 30 Revenue Estimates for Bill, Tax Notes Today, Feb. 16, 1993 [both available in LEXIS, Fedtax Library, TNT File.]

169. See Bittker, supra note 79 , at 780 .

170. See supra Table 1 , note 4.

171. See text accompanying notes 52-26. 
other tax decreases (increases) on relative prices as well as on the employment, consumption, savings, wages, interest, rents, and profits of the people whose change in distributional burdens is being assessed. When the changes in these relevant variables are likely small, their distributional effects may well be negligible and any "errors" reasonably, if not safely, disregarded. Likewise, the choice between distributing only the static revenue effects (JCT's proxy for "burden") and the total revenue effects is not important when the effect of the tax change on peoples' behavior is small. But when the tax changes and their likely consequences on behavior are large, confidence in the "truth" of quantitative estimates of distributional consequences diminishes. As I have demonstrated, necessary simplifying assumptions are commonplace, but they are very controversial.

My concerns expressed here should not be taken to imply that I believe distributional or revenue information to be unimportant or that policymakers should not be informed of the distributional or revenue consequences of their proposed actions. It is crucial, however, to distinguish the beneficial effects of academic, private, and staff analyses of such information in an effort to understand better the existing state of affairs or proposals for change to be considered in the future from the dangers of such information presented to policymakers in the form of supposedly definitive distributional tables at the time legislative decisions are being made. My principal thesis is that distributional information is far too important to be left to distributional tables. The information transmitted to policymakers through the current practice of producing distributional tables is simply bad information. Typically, it is both too much information and too little. Distributional tables not only are overly precise, but they also leave out important distributional matters. They completely conceal important differences among the families grouped together in one distributional classification. Distributional tables do not, for example, show how different age cohorts, types of families or regions of the country will be benefitted or burdened by tax changes. Indeed, distributional tables bury such information along with many other issues discussed in this Article.

The current use of revenue estimates is, if anything, even more troubling. Protected by supposed budget scorekeeping safeguards, policy proposals are manipulated to produce revenue results in a five-year budget window when the longer-term revenue consequences are known to be quite different from that within the budget window. The process should be revised to make explicit long-run comparisons of the budgetary effects of proposals in an effort to make legislators accountable for the long-term consequences of their decisions. Moreover, a range of estimated revenue effects should be given to Congress and the Administration. Unfortunately, Congress may-at least in one important respectbe moving in the opposite direction, tying a proposed constitutional 
amendment requiring a balanced budget to annual estimates of receipts and outlays. ${ }^{172}$

People seriously concerned with the tax policymaking process have reason to worry that the current use of both distributional tables and revenue estimates in tax policymaking may prove extremely costly to sensible tax policy. To take only one recent example, the substantial increases in the marriage penalties under the 1993 legislation occurred as a consequence of an effort to make both revenue estimates and distributional tables come out in a certain manner. The current emphasis on distributional tables and revenue estimates tends both to reify staff decisions about controversial matters and to tie legislators' hands in making considered policy judgments. Many thoughtful observers of the tax legislative process, including a Chief of Staff of JCT, have vigorously lamented the dominant role now being played in the tax legislative process by revenue estimates. ${ }^{173}$ There is a serious danger that distributional tables play an equally negative role. Indeed, some thoughtful observers believe this was the case in 1990. If current practices in constructing and using distributional tables had been in vogue then, they might well have stymied the 1986 tax reform process, although the overwhelming commitment of the relevant staffs to the substance of that legislation more likely would have induced them to put aside their "standard" practices for more creative uses of data to make sure that this did not happen.

In my view, the distributional tables now presented to members of Congress and other tax policymakers while legislation is being considered should be abandoned. Congress would be far better served if the relevant staffs coupled a verbal description of the overall distributional consequences of legislation under consideration (with doubts, controversial assumptions, and uncertainties of the sort detailed in this Article explicitly identified and discussed) with staff-produced examples of how the legislation under consideration would affect the taxes of specific examples of typical families. If a legislator were interested in a particular circumstance, examples could be readily produced with added facts, distinguishing, for example, taxpayers over 65 from younger families or couples where both spouses work from those with only one employed spouse. Both the qualitative information and the examples of how various families would be affected by the legislation generally would be noncontroversial among the staffs, and any significant disagreements among the staffs could be discussed in the presence of the decisionmakers. When offsetting tax increases or decreases are considered necessary for distributional reasons, staffs might also indicate their rough magnitudes. Indeed, staffs unight wish to refer for their own discussion to analyses of the sort they now make available to decisionmakers but with greater consideration of ambiguities, disputes and uncertainties of the sort I have detailed here.

172. See Taylor, supra note 153 , at 358 .

173. See Gutman, supra note 132. 
As examples of the kinds of qualitative distributional information I envision, the relevant staffs should inform members of Congress that substitution of a value-added tax for the income tax would reduce taxes for highincome families, but that this effect would be smaller if a longer time perspective-perhaps even a lifetime perspective-were taken; that integration of the corporate tax would be a tax reduction for higher income people to the extent that the incidence of the tax is now on owners of capital, but less so to the extent the corporate tax is borne by labor or consumers. Likewise, the staff should inform decisionmakers that a tobacco tax increase would be borne largely by younger low- and middleincome people and is regressive when viewed vis-a-vis annual income but perhaps proportional on a lifetime basis. The ongoing production of new distributional tables for policy alternatives should come to a halt.

No doubt, the views I am expressing here will be regarded by those who produce such data and perhaps by the economics profession at large as an effort to deprive legislators of the best data that economic science can now produce, given the time constraints that the legislative timetable demands. So be it. Ronald Coase, the Nobel Laureate in Economics, once remarked, "In my youth it was said that what was too silly to be said may be sung. In modern economics it may be put into mathematics."174 In an even less charitable moment, he observed: "If you torture the data enough, nature will always confess." 175

\section{ADDENDUM}

On March 23, 1995, after this Article went to press, the Wall Street Journal reported that the Treasury Department (OTA) and the Joint Committee on Taxation (JCT) made substantial changes in their methodologies for distributing benefits of tax reductions advanced by the new Republican House of Representatives majority. ${ }^{176}$ Both OTA and JCT reversed their positions on distributing changes in taxes versus changes in burdens for proposed capital gains tax rate reductions. OTA distributed the static revenue cost of the change as an estimate of the change in tax burdens (JCT's prior practice) and JCT distributed the actual anticipated change in taxes (OTA's prior practice). ${ }^{177} \mathrm{JCT}$ also abandoned its prior practice of allocating changes in corporate taxes to owners of capital and instead did not include any of the benefits of corporate tax reductions in its distribution tables. ${ }^{178} \mathrm{JCT}$ distributed tax reductions for the year 2000;

174. Ronald H. Coase, The Firm, the Market and the Law 185 (1988).

175. Ronald H. Coase, How Should Economists Choose? 16 (1982); see also Michael A. Fitts, Can Ignorance be Bliss? Imperfect Information as a Positive Influence in Political Institutions, 88 Mich. L. Rev. 917, 917-82 (1990).

176. Lucinda Harper, Treasury, Congress Disagree How Much GOP's Gains-Tax Cut Benefits the Rich, Wall St. J., March 23, 1995, at A2.

177. See supra Part II.C.1.

178. See supra text accompanying notes $73-80$. 
OTA continued to distribute tax changes as fully phased-in.179 As the Wall Street Journal accurately reported, "The result: The Treasury's changes make the Republican tax-cut bill look extremely generous to the rich. Changes by the congressional Joint Committee on Taxation make the same tax cuts look less generous to the wealthy." ${ }^{180}$

These methodological changes should shake anyone's remaining confidence that the various staffs' distributional tables discussed in this Article are-or even can be-driven by economic science rather than by politics. The mystery deepens as to why these distributional tables should be used to determme tax legislative outcomes.

I rest my case. 